\title{
The Effect of Using Instructional Program Based on the STEM (Science, Technology Engineering \& Mathematics) Approach in Teaching Mathematics on the Critical Thinking Skills of High School Students in the Riyadh Educational District
}

\author{
Mohammad Adnan Mohammad \\ Ejbara \\ Test Development Specialist \\ Qatar University Test Center \\ Deanship of General Studies \\ m.ejbara@qu.edu.qa
}

\author{
Yousef Muhammad Jabriel \\ Al-Isa \\ Teaching Supervisor and Self- \\ Development Skills Trainer \\ Riyadh Najd International Schools \\ yousef_alisa@yahoo.com
}

\author{
Mona Mohammad Mustafa \\ Khandakji \\ Department of Mathematics \\ Applied Science Private \\ University \\ khandakjimona@gmail.com
}

Received:25/6/2020

Accepted:9/8/2020

\begin{abstract}
:
This study aims to identify the effect of using a STEM-oriented (Science, Technology Engineering \& Mathematics) teaching program in teaching mathematics on critical thinking skills among high school students in the Riyadh educational region in the Kingdom of Saudi Arabia. The sample of the study consists of (88) male and female students selected randomly from the "Advance Schools for Smart learning" in Riyadh city, where the semi-experimental approach is used. The results of the study show that there are statistically significant differences between the averages of the degrees of analysis skill, induction skill, reasoning skill, skill of conclusion, and evaluation skill in favor of the experimental group. The results also showed a statistically significant difference between the mean scores for the analysis skill, the induction skill, the reasoning skill, the conclusion skill and the evaluation skill for the benefit of the experimental group. The results also show a statistically significant difference between the mean scores for the scale skills as a whole and for the benefit of the experimental group. The results of the study show that there are no statistically significant differences between the mean scores of the critical thinking test skills and the total score attributed to the gender variable (male and female). The study recommends adopting the STEM approach in teaching science, technology, engineering and mathematics subjects, and redeveloping and building the content of science and mathematics curricula for the secondary stage through relying on science standards for the next generation, and working on adopting a special curriculum to teach the STEM approach and include it in the next plan for general education stages.
\end{abstract}

Keywords: Smart Learning, Steam Teaching Approach, Critical Thinking. 


\section{أثز استخام برنامج تدريسي قائم على منحى التعلم الجذعي

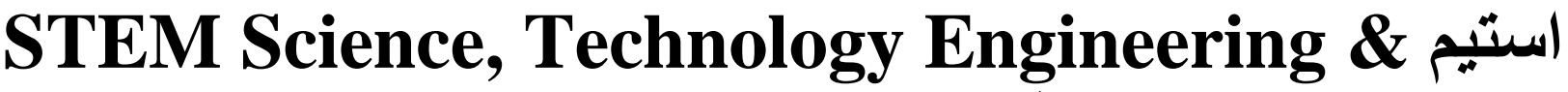 (Mathematics) الناقد لاى طلبة المرحلة الثانوية في منطقة الرياض الريات التعليمية}

د. يوسف محمد جبرائيل العيسى

مشرف تعليمي ومدرب مهارات تطوير الذات

مدارس رياض نجد العالمية

yousef_alisa@yahoo.com

قبول البحث: 2020/8/9
د. منى محمد مصطفى خندقجي

قسم الرياضيات

جامعة العلوم التطبيقية الخاصة

khandakjimona@gmail.com

د. محمد عدنان محمد اجباره

أخصائي تطوير اختبارات

مركز اختبارات جامعة قطر عمادة

الدراسات العامة

m.ejbara@qu.edu.qa

استلام البحث: 2020/6/25

الملخص

STEM (Science, Technology هدفت هذه الدراسة إلى تعرّف أثز استخدام برنامج تدريسي قائم على منحى التعلم الجذعي (Engineering \& Mathematics في المملكة العربية السعودية. تكونت عينة الدراسة من (88) طالباً وطالبة تم اختيارهم بطريقة عشوائية من طلبة "المدارس المتقدمة للتعلم الذكي"

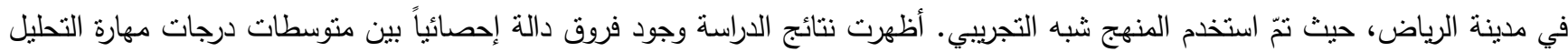
ومهارة الاستقراء ومهارة الاستدلال ومهارة الاستتناج ومهارة التقييم لصالح المجموعة التجرييية. كما بينت النتائج وجود فروق دالة إحصائيا بين متوسطات درجات مهارات المقياس ككل ولصالح المجموعة التجريبية. هذا وأظهرت نتائج الدراسة عدم وجود فروق دالة إحصائياً بين متوسطات دهات درجات مهارات اختبار التفكير الناقد، والدرجة الكلية تُعزى لمتغير الجنس (ذكر، وأنثى). أوصت الدراسة بتنّيّي منحى

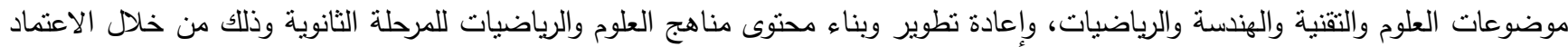

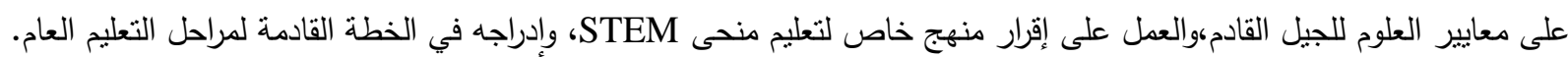
الكلمات المفتاحية: التعلم الذكي، منحى ستيم في التدريس، التفكير الناقد.

التعليم كما يقول كين روبنسون (Robinson) (38) هي: "إننا نعرف

المقدمة

بالفعل ما ينجح، لكننا لا نفعله بالقدر الكافي".

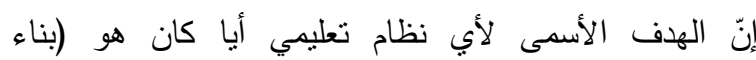

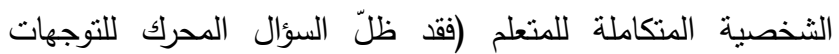

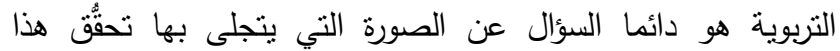

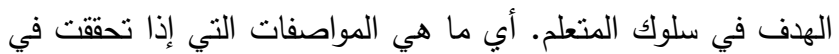

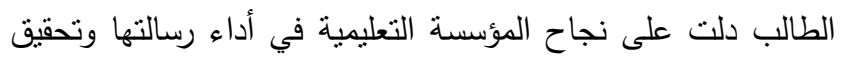

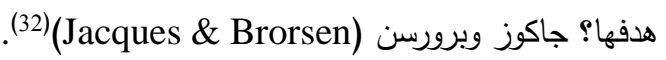
إن إجماع التربويين اليوم يكاد ينعقد على أن المهمة الأساسية للمؤسسات التعليمية هي إعداد المتعلمين للمستقبل وليس في تزويد

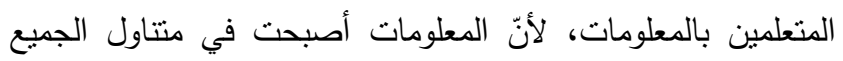

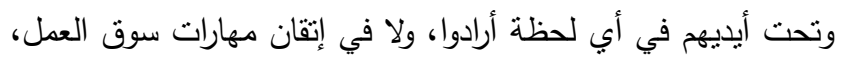
فسوق العمل يتطلب من المهارات مالا يمكن حصره فضلاً عن إتقانه،

يدين العالم من حولنا في كل ما أحرزه من تقدٍٍ في مجالات العلوم والفنون والآداب، وما نوصل إليه من حضارة إنسانية شامخة

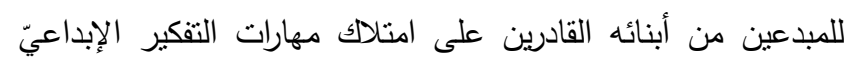

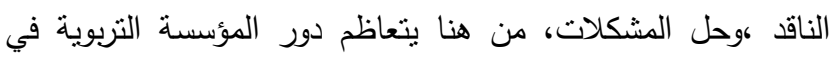
إعداد أفراد قادرين على التفكير وحلّ المشكلات غير المتوقعة. فقد بات هناك اتفاق يكاد يكون عاماً بين الباحثين على أن التفكير بكافة

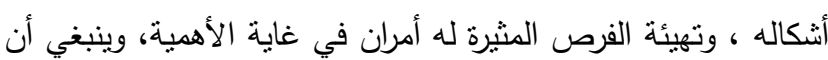
يكون التفكير هدفاً رئيساً لمؤسسات التربية والتعليم.

إننا نواجه مستقبلا غير واضح المعالم أو مؤكدا تماما، فالإجابة

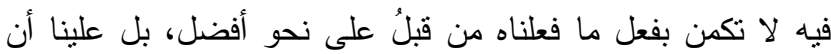
نفعل شيئا مختلفا وجديدا. والمفارقة الكبرى في الأزمة التي نواجه 
بإنشاء عدة مدارس تتبنى هذا الهنحى، وقامت بإلحاق الطلبة المتميزين والمتفوقين بها.

وتظهر التوجهات العالمية زيادة الاهتمام بهذا المنحى في

التعليم، فقد عُد في الولايات المتحدة الأمريكية في شهر يونيو حزيران

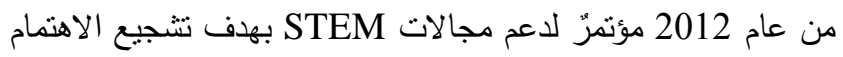

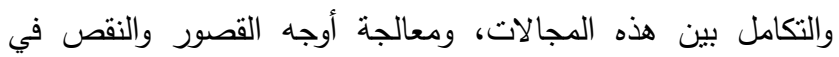
المهارات ذات الصلة (البشير)(2).

من خلال ما سبق، وفي ضوء عدم الرضا عن مستويات الطلبة

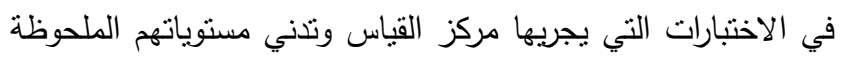

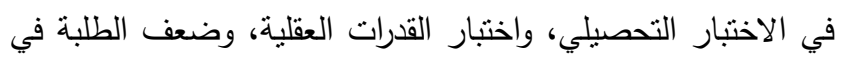

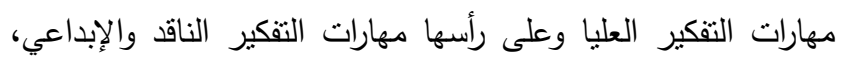

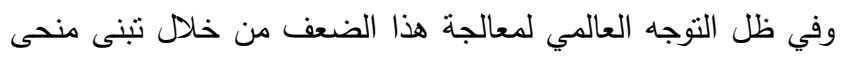
التعليم القائم على STEM يرى الباحثون الحاجة لبحث أثر استخدام برنامج ندريسي قائم على منحى STEMScience, Technology Engineering \& Mathematics

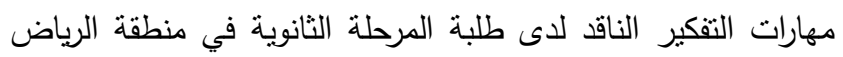
التعليمية في المملكة العربية السعودية.

مشكلة الاراسة

عند الحديث عن الجهود التي تبذلها المملكة العربية السعودية في تعزيز الثقافة العلمية تبرز جهود نطوير مناهج العلوم والرياضيات، وذلك عبر مشروع نطوير العلوم والرياضيات القائمة على مناهج

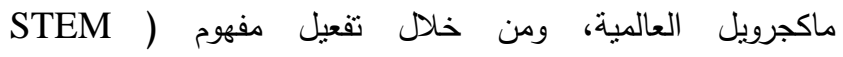
EDUCTION العام لتحسين أداء الطلبة في العلوم والتقنية والهندسة والرياضيات،

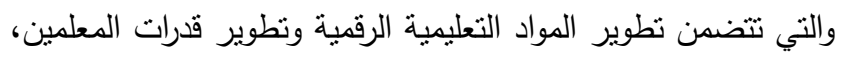

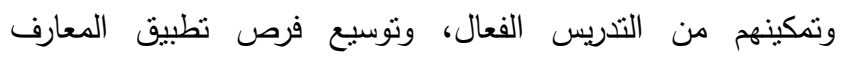
والمهارات العلمية، وبناء الاتجاهات الإيجابية، وتطوير النقافة العلمية

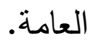

يركز التعليم القائم على منحى STEM على تدريس الموضوعات المتكاملة للعلوم والثقنية والهندسة والرياضيات، وينظر

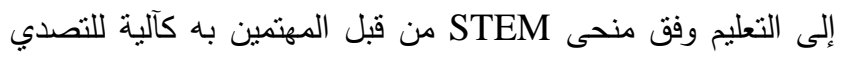
إلى ضعف نتائج مخرجات تدريس المواد الأربع بشكل فردي باستخدام

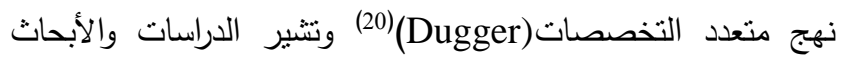

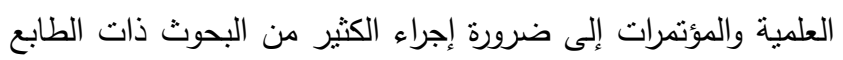
الكَّي أو النوعي حول ممارسات المعلمين واتجاهاتهم وأدائهم، وأوجه داته التعاون فيما بينهم حول مجالات تخصص STEM وكذلك الحاجة إلى إجراء أبحاث تتتاول الكيفية التي يفهم من خلالها STEM، والكيفية التي يتم بهاء التدريس في برامج إعداد المعلمين، والكيفية التي لئي يتم من خلالها إعداد المعلمين وتتميتهم في هذا المجال ( Gonzalez .$^{(24)}$ \& J.Kuenzi

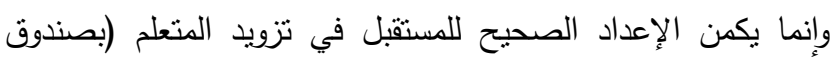
أدوات) أو (سلة مفاتيح) أو (استراتيجيات عمل) أو (أدوات للتفكير)

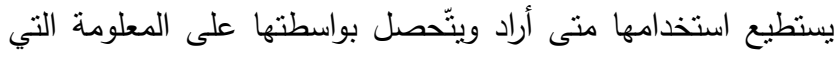

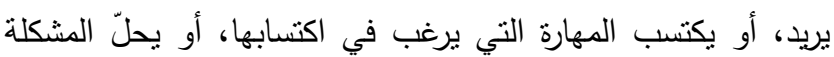

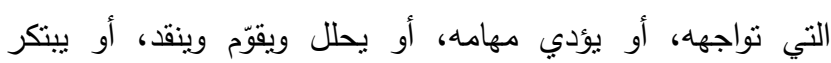
ويبدع (MacFarlane)

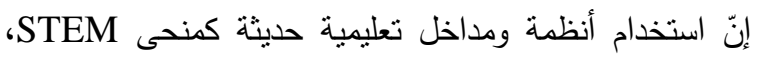
والذي يعني تدريس موضوعات العلوم والتقنية والهندسة والرياضيات Science, Technology, Engineering \& Mathematics بشكل متكامل ومدمج، وهو تعلُّم يؤكد على بناء وتعزيز مهارات

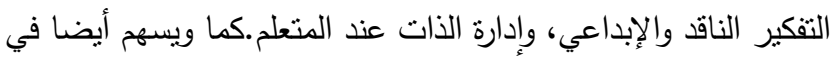
محو الأمية التكنولوجية واكتساب المهارات اللازمة من خلال عملية التصميم الهندسي،والذي يتطلب تفكيرا ناقداوإبداعيا. إنّ الاقتصاد المعرفي يدعو إلى إعادة هندسة أساليب التعلم

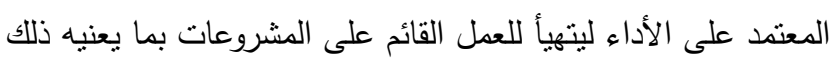
من تطبيق حقيقي للعديد من الخبرات المعرفية المعتدة على طرق التفكير، حيث تؤكد الأبحاث المعاصرة على تعزيز قدرات الطلبة على لقي

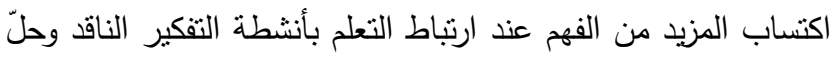
المشكلات ذات المغزى، وعند فهم سبب ووقت وكيفية ارتباط هذه المهارات والحقائق. (Bransford)(16).

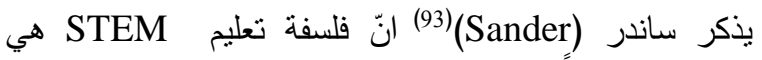
محصلة جهود إصلاح التعليم للعلوم، والثقنية، والهندسة، والرياضيات

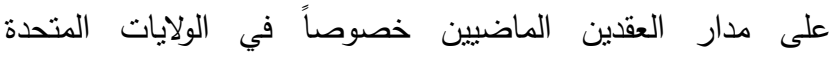
الأمريكية، ضمن رؤية شُشخرالعلم لجميع الأمريكيين.

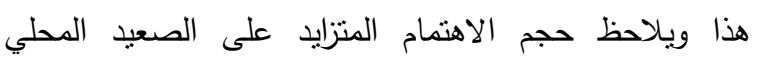
والعالمي اتجاه منحى STEM، وأهمية إعداد المتعلمين في مجالاته،

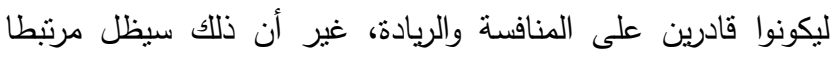

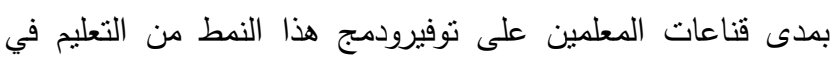
ممارساتهم التدريسية (خجا ومحيسن) (7). لقد أبدت الدول المتقدمة كالولايات المتحدة الأمريكية،وبريطانيا اهتمامها نحو التنريس وفق منحى STEM، حيث قامت بإنشاء المدارس التي تهنم بهذا النوع من التعليم. ومؤخرا بدأت الدول العربية تبدي اهتماما بالتعليم وفق منحى STEM فنظمت الجمعية العربية

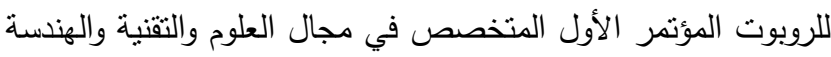
والرياضيات STEM في تشرين الأول من عام 2016، حيث ركزعلى

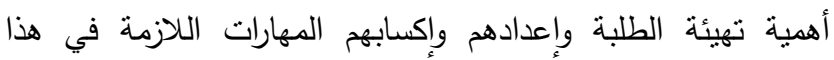
المجال (القتامي) تهي). وفي المملكة العربية السعودية نَصَّ برنامجُ التحول الوطني على لهي

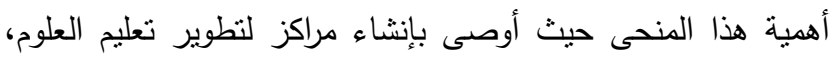
والتقنية والهندسة، والرياضيات STEM (برنامج التحول الوطني2016-2020). وفي جمهورية مصر العربية قامت الحكومة 
الصفي. حيث تشكل فائدة كبيرة للعاملين في الحقل التربوي، من خلال التعريف بمنحى STEM، وبعض المهارات التي ينميها

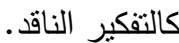

3. نساعد هذه الدراسة مصممي المناهج ومُطوِربها على استخدام منحى تدربس موضوعات العلوم والتقنية والهندسة والرياضيات STEM وطرائق واستراتيجيات التدريس.

\section{حدود الاراسة ومحدداتها}

1. اجريت الدراسة في المملكة العربية السعودية، في العاصمة الرياض.

2. طبقت هذه الدراسة في منطقة الرياض التعليمية للفصل الأول للعام

$$
\text { الدراسة } 2019 \text { - } 2020 .
$$

3. تحدد تطبيق هذه الدراسة في" المدارس الأهلية المتقدمة للتعلم الذكي "بالرياض لاستخدامها أسس التعلم الذكي في التدريس. التعريفات الاصطلاحية والإجرائية: 1. المنحى الجذعي في تدريس موضوعات العلوم والتقنية والهندسة والرياضياتSTEM.ويتحدد المفهوم من خلال أنه اختصار لمسميات تخصصات: العلوم والتقنية والهندسة والرياضيات.فهو تعليم يجمع بين التخصصات السابقة في موضوع واحد. حيث تتوفر للطلبة فرصة لفهم العالم الذي نعيش فيه فهما شاملا منكاملا بدلا من تعلم أجزاء وقطع منتاثرة (Williams)(40). 2. ويعرفه ساندر (Sander) (39) بأنه تعليم يشمل النهج الذي يسعى لاستكثاف التذريس والتعليم فيما بين انثين أو أكثر من تخصصاتSTEM وواحد أو أكثر من المواد الدراسية الأخرى. 3. ويُعرف (Erdogan \& Stuessy) المنحى الجذعي STEM) المي بأنه منحى متعدد التخصصات، يدمج تخصصات مختلفة معا، ولا يقسم محتوى تخصص معين؛ حيث تتكامل المفاهيم العلمية

$$
\text { الراسخة مع الواقع الطبيعي. }
$$

\section{STEM التعريف الإجرائي لـ ST}

هو دمج مقصود وهادف ومتكامل لعدة تخصصات وذلك من خلال التركيز الهادف على الطبيعة الترابطية والتكاملية ما بين العلوم والتقنية والهندسة والرياضيات، حيث تقترن المفاهيم مع بعضها، والهدف من ذلك غرس فهم أعمق لكل موضوع من خلال التركيز على المفاهيم والمبادئ، والنظريات،ومع إنتاج محتوى المناهج التعليمية وأساليب التدريس المستدة على المشاريع وحل المشكلات في

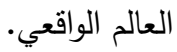

التفكير الناق

Reflective التقكير الناقد هو شكل من أنشكال التفكير التأملي Thinking

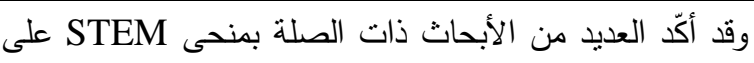
الأهمية الكبيرة لدمج برنامج STEM في سوق العمل حيث أكد تقرير" ارتباط المدارس بالصناعات وتعليم STEM في بريطانيا " على ضرورة ربط تعليم STEM بالمهن مع إناحة العديد من الفرص Mann لتعزيز تعلم الرياضيات والتصاميم التكنولوجية والهندسية . $^{(36)}$ (\&Oldknow) مما سبق، وانطلاقا من إحساس الباحثين بأهمية التعلم المرتكز على منحى STEM في التقدم العلمي والاقتصادي، وأهمية الاعتماد في التدريس الصفي على هذا المنحى جاءت هذه الدراسة لتكثف عن أثز استخدام برنامج تدريسي قائم على منحى STEM في تدريس الرياضيات على مهارات التفكير الناقد لاى طلبة المرحلة الثانوية في برتي منطقة الرياض التعليمية في المملكة العربية السعودية. ويمكن صباغة مشكلة البحث في السؤال التالي: ما أثر استخدام برنامج تدربسي قائم على منحى STEM في تدربس الرياضيات على مهارات التفكير الناقد لاى طلبة المرحلة الثانوية في

منطقة الرياض التعليمية في المملكة العربية السعودية؟ ويتقرع عن هذا السؤال الرئيس الفرضيتان التاليتان: لا يوجد فرق ذو دلالة إحصائية عند مستوى دلالة (0.05 $\square$ (ب) بين متوسطات درجات طلبة المجموعة التجريبية، ودرجات المجموعة الضابطة لمهارات مقياس التفكير الناقد لـ كاليفورنيا (2000) (مهارة التحليل Analysis Skill، مهارة الاستقراء Induction Skill، مهارة الاستدلال Inference Skill، مهارة الاستتناج Deductive، Skill مهارة التقييم Evaluation Skill) تُعزى لطريقة التدريس (استخدام برنامج تدريسي في الرياضيات قائم على منحى نعى ستيمSTEM، الطريقة التقليدية). لا يوجد فرق ذو دلالة إحصائية عند مستوى دلالة (0.05 $\square$ (ب) بين متوسطات درجات طلبة المجموعة التجربيية، ودرجات المجموعة الضابطة لمقياس التفكير الناقد لـ كاليفورنيا (2000) (مهارة التحليل Analysis Skill الاستدلال Inference Skill، مهارة الاستنتاج Deductive Skill، مهارة التقييم Evaluation Skill) تُعزى لمنغير الجنس(ذكر، أنثى). أهمبة الدراسة 1. تُعدّ هذه الدراسة من الدراسات الحديثة التي حاولت الكثف عن أثر استخدام برنامج تدريسي قائم على منحى STEM في تدربس هده

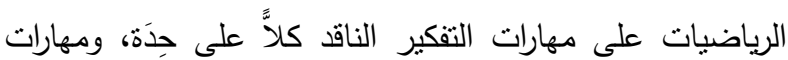
التفكير الناقد ككل لاى طلبة المرحلة الثانوية في منطقة الرياض التعليمية في المملكة العربية السعودية. 2. تكمن أهمية النتائج التي قد تخرج بها الدراسة الحالية في أنها قد تساعد قادة وقائدات المدارس، والمعلمين والمعلمات والمشرفين والمشرفات، في تبني المنحى الجذعي STEM في التعليم والتعلم 
المجلة الدولية لضمان الجودة - المجلد الثالث - العدد الثاني، 2020.

والفعالية في الاستكثاف HeuristicsEffective، والعادات العقلية

.Habits of Mind

ومما سبق يتضح صعوبة تحديد تعريف للتفكير الناقد، ويمكن

تجاوز ذلك من خلال تحديد الملامح الرئيسة له، فالتفكير الناقد

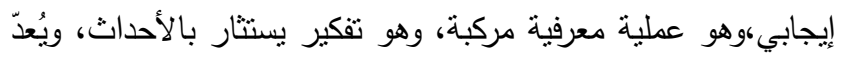

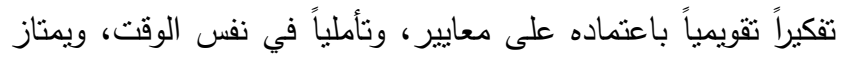

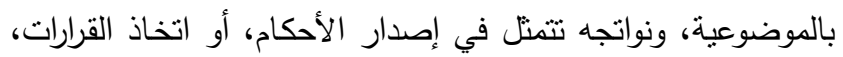

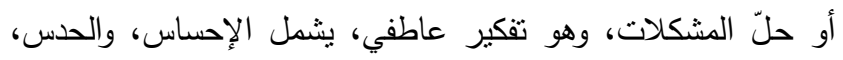

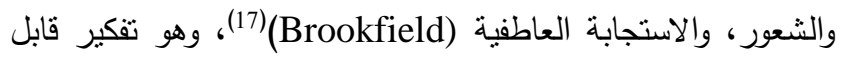

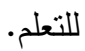

ويتبنى الباحثون التعريف الذي وضعه(القتامي)(4) للتفكير الناقد وهو قدرة الفرد عل بالفحص الدقيق للمواقف التي يتعرض لها، والتمييز

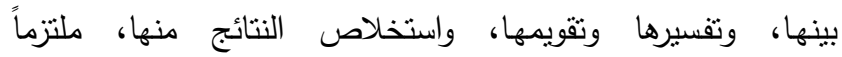
بالموضوعية والحياد.

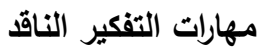

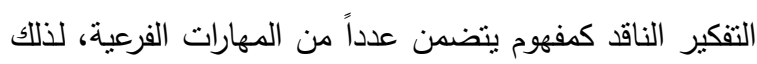

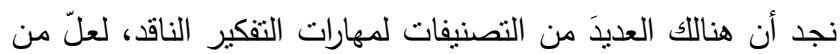

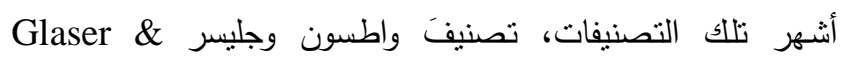

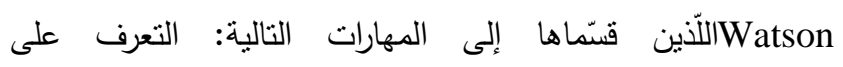
الافتراضات، والتفسير ، والاستتباط، والاستتناج، وتقويم الحُجج. أما تصنيف نيدير Needier، فقد أوضح أن التفكير الناقد ينكوّن من اثنتي عشرةَ مهارة، تتمثل في: تحديد المشكلات، وتمييز أوجه الثبه والاختلاف، وتحديد المعلومات، وصياغة الأسئلة، وتقديم

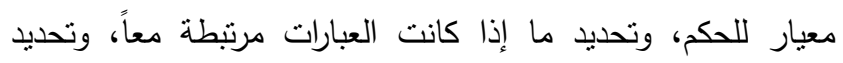

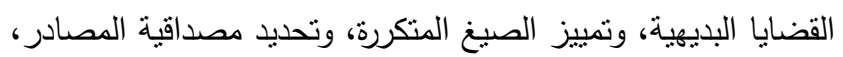
وتمبيز الاتجاهات المختلفة، وقدرة البيانات وكفايتها، والتنتؤ بالنتائج المدكنة (جروان) (6).

ويصنف أودال ودانيالز Daniels \& Udall مهارات التفكير

الناقد في ثلاث فئات هي: الاستقراء، والاستتباط،، والتقويم(جروان)(6). ويلخص بول وسكريفينScriven\& Paul التفكير الناقد في مهارات وأنشطة تتضمن مايلي: القدرة على التفسير، والتقويم، والملاحظة،

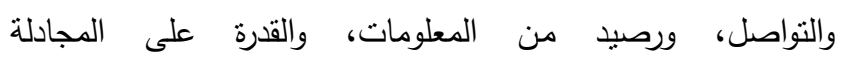
${ }^{\text {(23) (Fisher) }}$

يلاحظ مما سبق أن المهارات التي اقترحها واطسون وجيلسر تتطوي في إطار بُعدين: بُعْدٍ معرفي يستدعي وجود إطار لتحليل

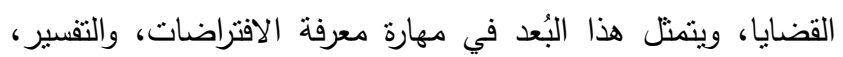

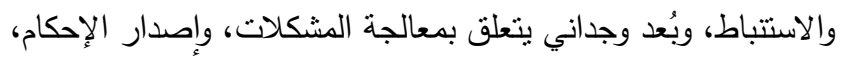

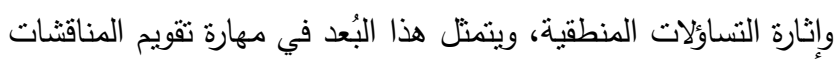

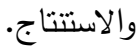

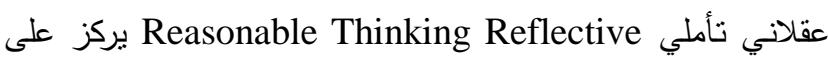
اتخاذ القرار، وهو نمط من التفكير يتبع المنهج العلمي. التعريف الإجرائي للتفكير الناقد

هو العمليات العقلية التي يقوم بها الطلبة (المجموعتان

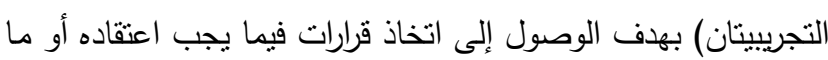

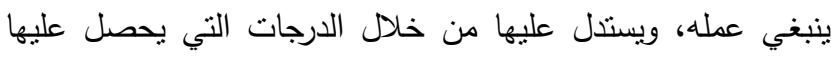

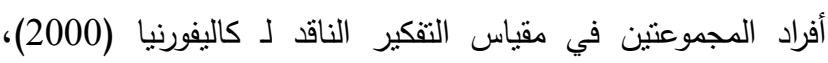
(شطناوي)(9) الذي اعتمده الباحثون في هذه الدراسة.

الإطار النظري والدراسات السابقة أولا: الإطار النظري

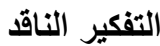

حاول العديد من الباحثين تقديمَ تعريفٍ واضحِ للتفكير الناقد، إلا

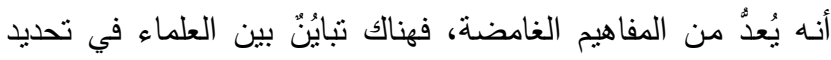

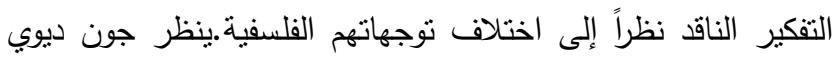

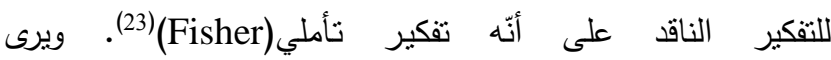
جليسرGlaser أنّ التفكير الناقد يتضمن ثلاثةًَ جوانب، هي: النزعة

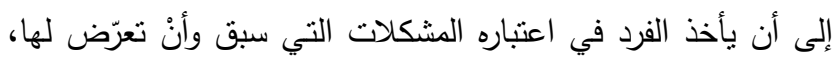

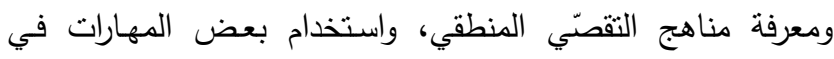

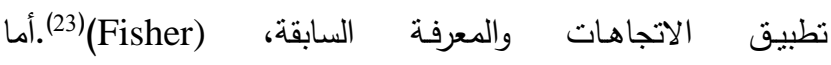
(13)(Astleitner) Thinking Reflective Reasonable أحد مهارات التفكير العليا Thinking Order Higher التي تُعنى

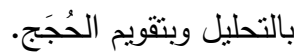
ديانا هالبرن(Halpern)(26) ترى أنه تفكير تشتخدم فيه المهارات المعرفية. فهي نتظر إليه بأنه يتبع المنهج العلمي، فالمنهج

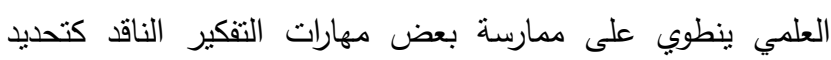
المشكلة، ووضع الفروض، وجمع المعلومات، وفحص مدى صحتها،

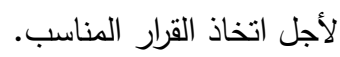

وهناك من برى أن التفكير الناقد عملية معيارية قوامها أنه

تفكيرّ مجرد ذو طبيعة تقويمية تتعلق بالموقف الذي يراد تقويمه (أبو لتون

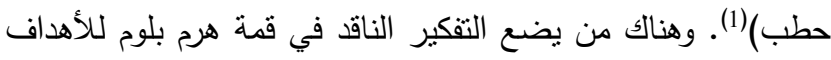
المعرفية (Huitt) جروان بدوره يشير إلبه باعتباره نشاطاً عقلياً مركباً وهادفاً، محكوماً بقواعد المنطق والاستدلال (جروان)(6).وفي نصور للتبنكير

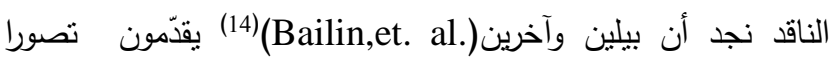
اللتفكير الناقد يشتمل على خمسة عناصر أساسية هي: القاعدة المعرفية Background Knowledge، والمعرفة الإجرائية بمعايير

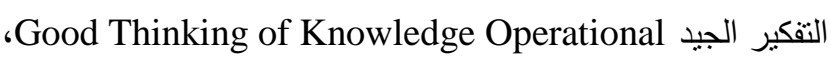
ومعرفة المفاهيم النقية:Knowledge of Critical Concepts، 


\section{STEM تصنيف مدارس}

توجد عدة تصنيفات لمدارس تعليمSTEM فهناك من يصنفها

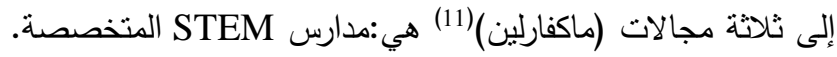
وهي مدارس نركز على تعليم STEM بشكل دائم، ومدارس تعليم STEM كبرامج في الددارس، وبرامج تعليم STEM الداخلية. ويُرجع الباحثُن التتوع في تصنيفات مدارس كثيرة من أهمها ما أورده (Dugger)

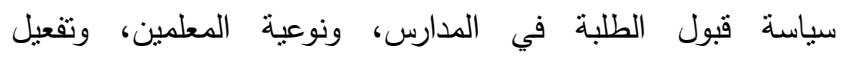
دور STEM في إعداد الطالب لاحتياجات القرن الواحد والعشرين. وتختلف مدارس STEM في نواحِ كثيرة، لكنها تشترك في

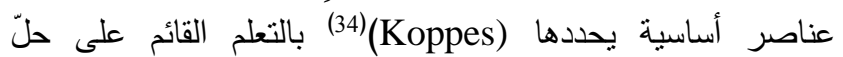

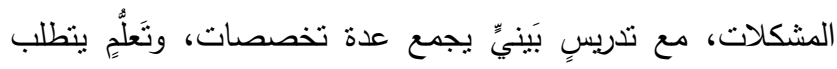

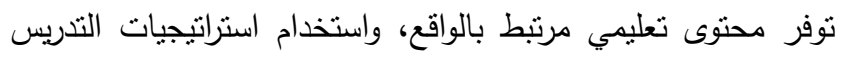
المنمايز، واستخدام عمليات التقويم لتوجيه تعلم الطلبة، وتعزيز قنوات

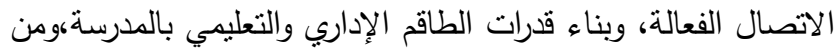

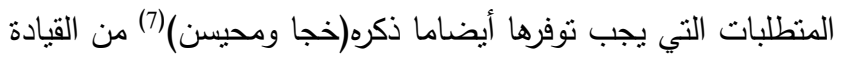
الفاعلة، والقدرات العالية للمعلمين، واعتماد الطالب محورا للعملية

التعليمبة.

وتُنظّم مناهجُ STEM بطريقة يتم من خلالها الربط بين الأنشطة بشكل تكاملي بحيث يتمحور النشاط حول فكرة معينة.

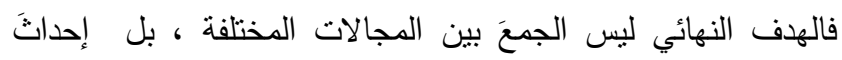
عملية تكامل وصولا إلى الهدف النهائي المراد تحقيقه من هذه العملية

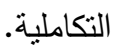
لقد وصف التقرير الذي أصدرته الأكاديمية الوطنية للعلوم في

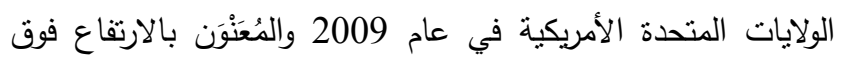
العاصفة المتلبدة Rising Above the Gathering storm) إطار فارة المبادرة، حيث نركزت المبادرة على ثلاثة محاور هي: تحسين

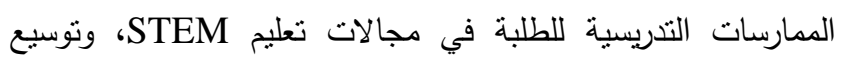
فرص التعليم، والحياة الوظيفية الملائمة، وتمكين معلمي العلوم لطالئ والرياضيات من مهارات تعليم STEM. وقد ذكر تقرير STEM Integration K-12 Education:Status Prospects, and an STEM التكامل بين غايات تدريس:Agenda for Research

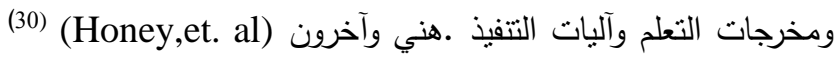

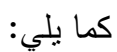
1الغايات وتشمل غايات الطلبة وتتكون من ثقافة تعليم STEM،

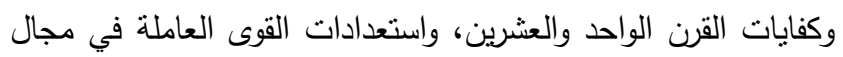
وتخصصات STEM، والاهتمام والمشاركة، وغايات المربين وتتضمن زيادة المحتوى التعليمي لتعليم STEM. مخرجات التعلم وتحتوي على مخرجات التعلم للطلاب، ونتمنل بكفايات القرن الواحد والعشرين، والتعلم والإنجاز، ومجالات التوظيف المرتبطة بـ STEM لمعرفة احتباجات سوق العمل، ومخرجات التعلم
ثانيا: المنحى الجذعي في التدريس STEM

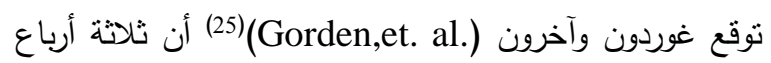
الوظائف في سوق العمل الأمريكي تحتاج بحلول العام 2020 إلى دأى عمالة ذات مهارات عالية، لذلك أصبح على النظام التربوي تخريج متعلمين قادرين على حل المشكلات، والتوصل إلى ابتكارات

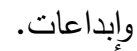

وقد أورد التقرير الذي أصدرته الأكاديمية الوطنية للعلوم في أمريكا في عام 2007 والمعنون "بالارتفاع فوق العاصفة المتلبدة" Rising Above the Gathering storm"(Agend Academy, (12) نوصية لتحسين تدريس العلوم والرياضيات من A Academy) الروضة وحتى الصف الثاني عشر تتصُّ على إنثاء مدارس ثنانوية

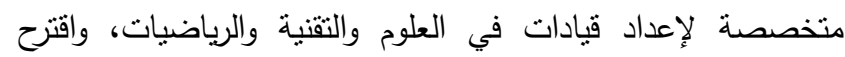

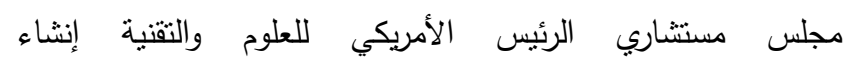
مدارس STEM. وشدد على أن هذا النوع من الددارس يمنل مصدراً

$$
\text { وطنيا فريداً من نوعه (ماكفارلين) (11). }
$$

ويشير (Harrison \& Royal) من أهم البرامج التي تبنتها بريطانيا والذي تم تحديده في الفترة ما بين عام 2004 و2010 وذللك بإضافة أنشطة ومهارات في مجال بلئال

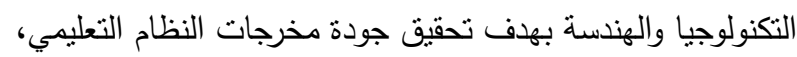
ويُعدُّ تعليم STEM من أهم التوجهات الحديثة في تعليم

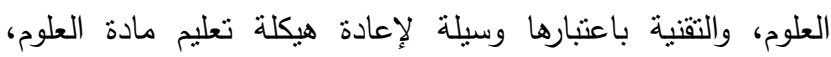

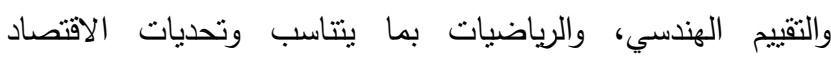
العالمي(Barcelona) هذا ويعتبر هنحى STEM دذخلاً يُبْنى للتعلم، حيث تثقابل

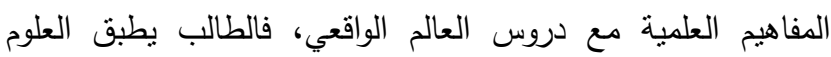

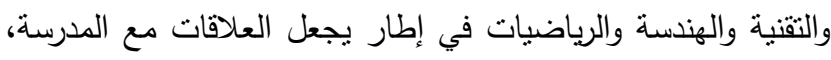

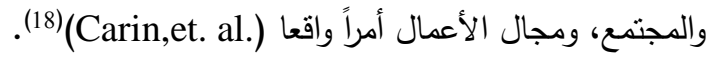

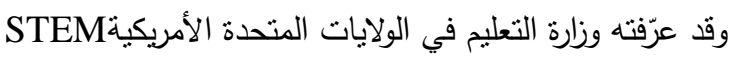
أنه" تلك البرامج التي تسعى إلى تعزيز العلوم والتقنية والهندسة

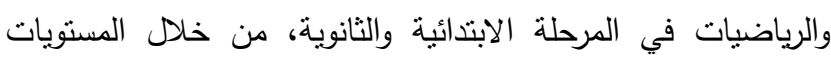
العليا" (Ministry of Education)( إن من أهم مقومات نجاح التعليم القائم على منحى

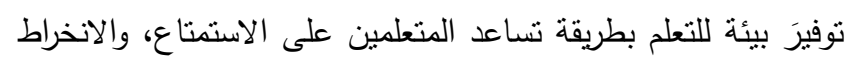
في وُرش عمل تكامل بين فروع العلوم، وتمكنه من معارفهر

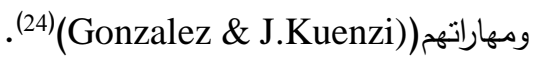
ويرى (Fang) (22) أن الطلبة الذين خضعوا للاراسة وفق منحى (Kن) STEM أظهروا حماسة بصورة إيجابية تجاه هذا المنحى والتعلم بشكل عام. 


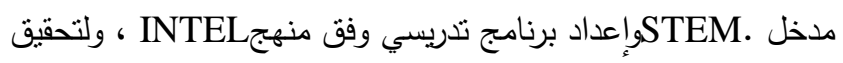
أهداف الدراسة استخدمت الباحثة المنهج الوصفي التحليلي من خلاد

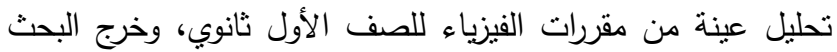
بعدة نتائج من أهها: تحليل المحتوى وفق معايير العلوم للجيل القادم Nتنائج تحليل محتوى( مدخل إلى علم الفيزياء) من الفصل الدراسي الأول لمقرر الفيزياء في ضوء معتئ معايير العلوم للجيل القادم NGSS 23\% بينما احتلّ محورا طبيعة العلوم المرتبطة بالممارسات والمفاهيم الثاملة وتوقعات أداء الطلبة لأنشطة العلوم والهندسة المرنبة الثانية بنسبة21\%. وفي ضوء النتائج أوصت الدراسة بضرورة تبني التصور

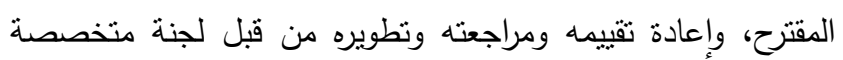

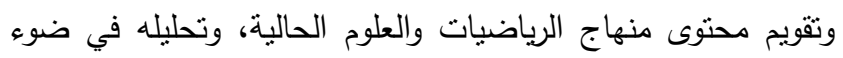
معايير العلوم للجيل القادم NGSS للتعرف على واقع هذا المحتوى لئي

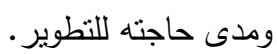
كذلك هدفت دراسة (فهمي)(10) إلى استقصاء التعلم القائم على لـ فئل

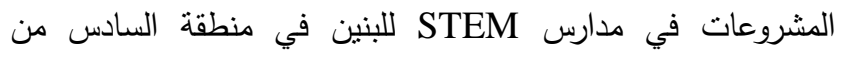

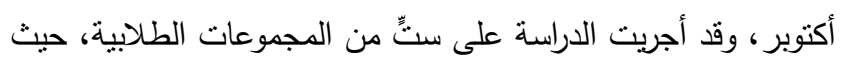
تتاول الباحث محورين اثثين: الدحور الأول يتتاول تصورات الطلبة الثبت

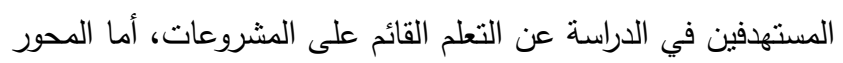

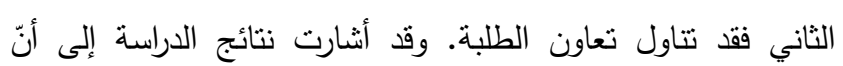
الطلبة قادرون على التعبيّر عن تصورات واضحة، كما أنهم بعتقدون

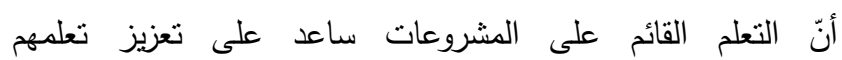

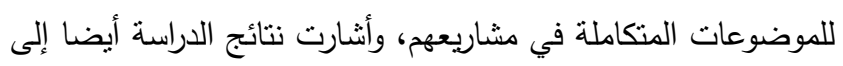

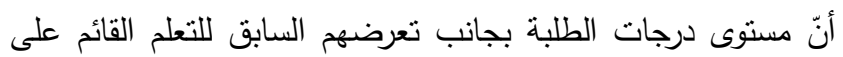
المشروعات قد أثز في تصوراتهم على ذللك التعلم.

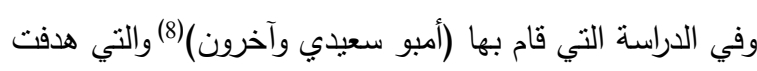

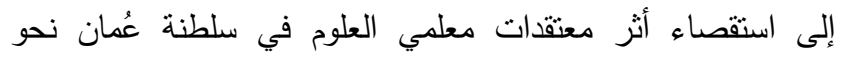
تدريس موضوعات STEM وعلاقتها ببعض المتغيرات، استخدم

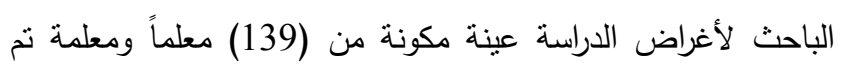
اختبارهم بطريقة عشوائية، وتم تطبيق مقياس معتقدات نحو تعليم عليهم، وقد قُسم المقياس إلى محورين هما: المعرفة بتعليم STEM

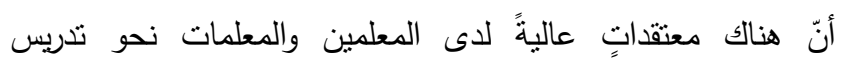

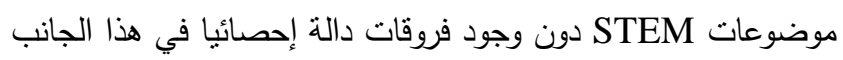

$$
\text { لكُتغيري الخبرة والجنس. }
$$

وهدفت دراسة (الثحيمية) (3) إلى استقصاء أثر استخدام تعليم

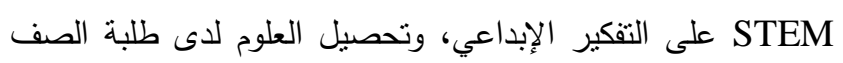

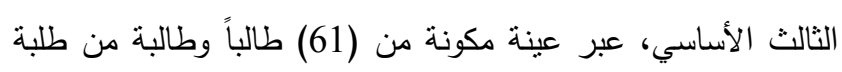
الصف الثالث الأساسي في مسقط، نم نوزيعهم على مجموعتين: الأولى تجريبية درست العلوم بطريقة STEM من خلا دليل الأنشطة

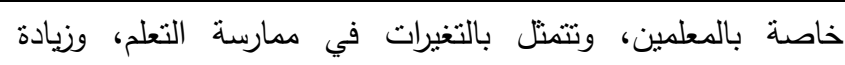
المحتوى المعرفي والتنربوي لتعلم STEM. التتفيذ ويتكون من إعداد التصاميم التعليمية الخاصة ب STEM.

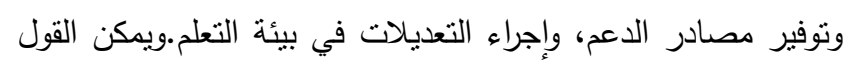

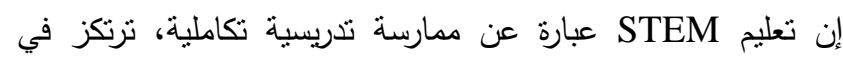

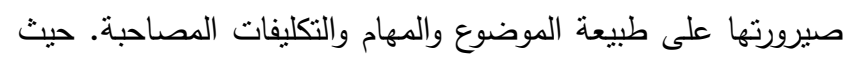

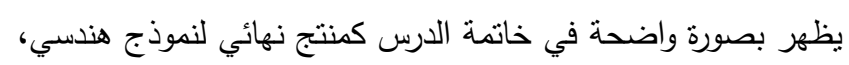

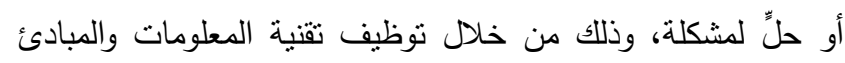

العلمية،

\section{خصائص درس نمونجي للتعلم وفق منحى STEM}

يتميز درس STEM بتكامله بين الدجالات الأربعة. وفيما يلي بعض الخصائص لدرس STEMنموذجي أوردها (ماكفارلين) (11)بيكن

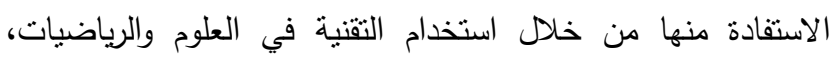

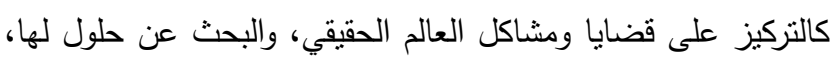

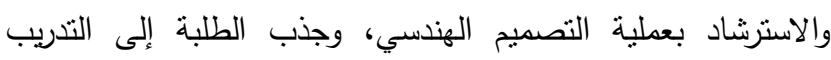

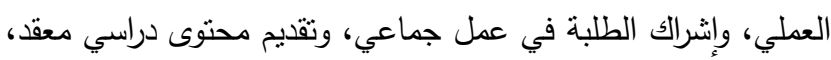

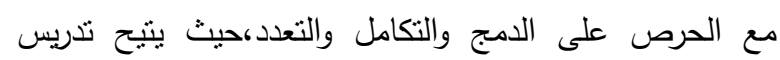
الاحتمالات للحلول الإبداعية غير الكنوقعة. ويرى الباحثون أنّ تعليم STEM لا يمكن اعتباره طريقة من

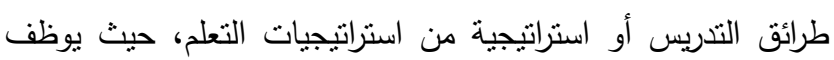

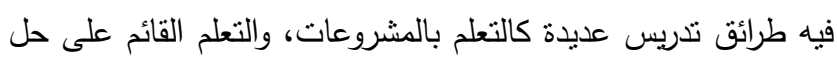

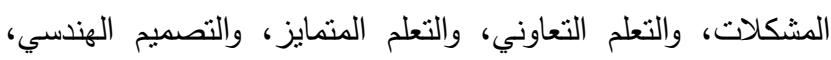
ودمج مهارات التفكير للقرن الواحد والعشرين. ثانيا: الاراسات السابقة تتاولت دراسة (القتامي) (4) أثز استخدام مدخل STEM لتدريس

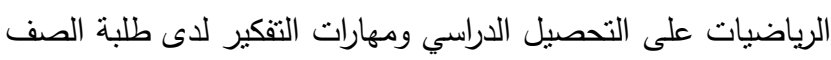

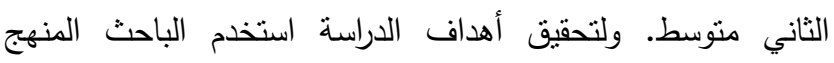
التجريبي، حيث اختار مجموعتين إحداهما ضابطة، والأخرى تجريبية

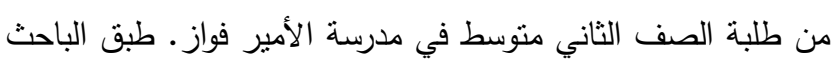

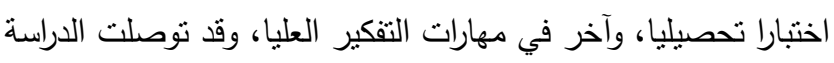

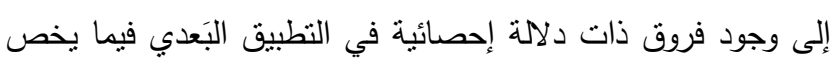

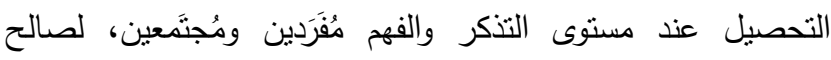
المجموعة التجريبية. ووجود فروق ذات دلالة إحصائية في النطبيق

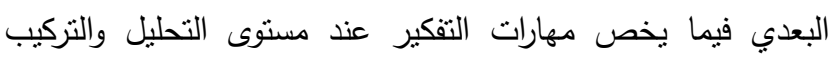
والتقويم مُفَرَدة ومُجنَّعة، لصنالح المجموعة التجريبية.

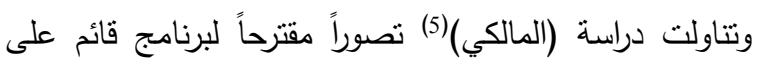
المدخل الجذعي STEM في الندريس وفق منهج INTEL المستتد على المشروعات. ولتحقيق أغراض الدراسة حدت الندات الباحثة قائمة

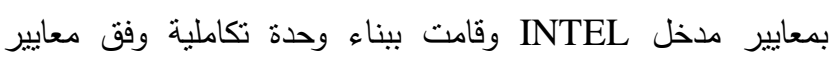


إحدى المدارس، بينما طبق المنهج السائد قي الرياضيات مع (350)

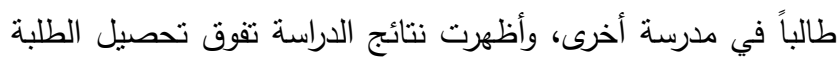
الذين درسوا العلوم والرياضيات بالطريقة السائدة مقارنة بتحصيل الطلبة الذين استخدما تعليم STEM، هذا وتتثير نتائج الدراسة إلى دالى

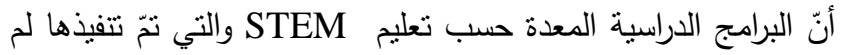

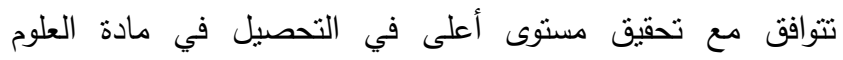

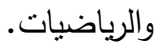

\section{التعقيب على الدراسات السابقة}

من خلال استعراض الباحثين للاراسات السابقة بشكل عام

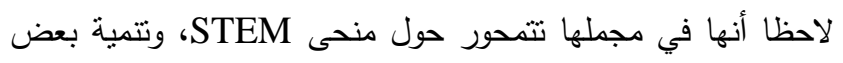

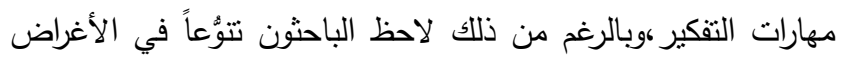
والأهداف من دراسة إلى أخرى.ورغم الاختلافات الواضحة فيما بينها

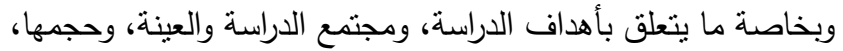
وتفسيرات الباحثين لنتائجها إلا أنها أجمعت بشكل كبير على نوظيف منحى STEM في التعليم، وفي تطوير محتوى المناهج الدراسية لمواد

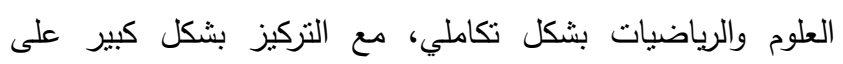
أساليب واستراتيجيات التنريس الحديثة باعتبارها من أهم منطلبات التعليم في العصر الحديث لكونها قوة فاعلة تتيح تيسير عمليات التعلم

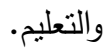
وقد تقاطعت الدراسات السابقة التي تم عرضها مع الدراسة

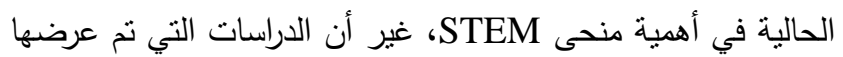

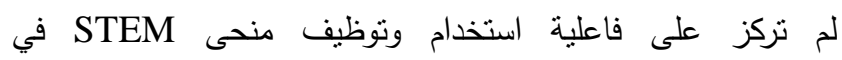
التعليم،وأثره في تتمية مهارات التفكير الناقد كـ (مهارة التحليل Analysis Skill الاستخلال Inference Skill، مهارة الاستنتاج Deductive Skill، مهارة التقييم Evaluation Skill)، ومهارات التفكير الناقد ككل، والذي ركز الباحثون عليه في دراستهم الحالية، وهذا ما يميز هذه وارته الدراسة عن غيرها من الدراسات السابقة الأخرى. وقد استفاد الباحثون من الدراسات السابقة التي نم تتاولها في كيفية بناء أدوات الدراسة،

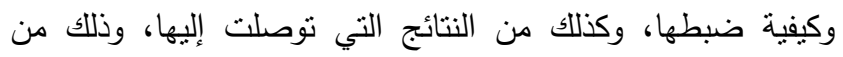
خلال ربط نتائج الدراسة الحالية بنتائج هذه الدراسات مع من مراعات اختلاف طبيعة كل دراسة نم تتاولها. الطريقة والإجراءات البرنامج التدريسي

قبل البدءء بتطوير البرنامج التدريسي تمّ مراجعة الأدب التربوي،

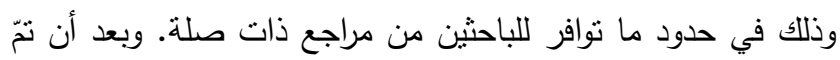

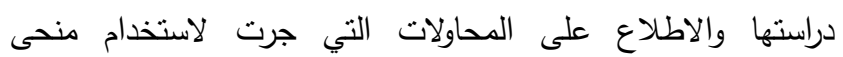
في المواقف التعليمية في المملكة العربية السعودية، وبعض جل دول العالم تّّ تحديد الإطار العام للبرنامج التعليمي، والذي انشتمل

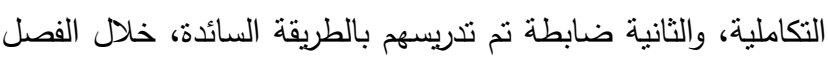
الدراسي الثاني من العام الدراسي 2015. تكونت أداة الدراسة من "مقياس تورانس للتفكيّر الإبداعي"، واختبار تحصيلي في مادة العلوم مكون من (16) فقرة، ما بين مقاليه

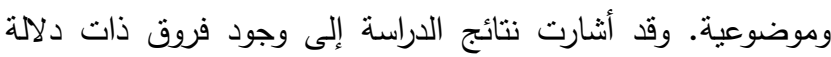

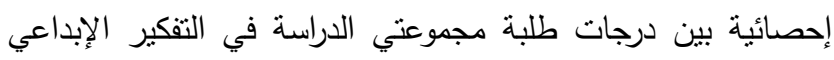
والتحصيل؛ لصالح المجموعة التجريبية، كما أظهرت نُمُوًاً في لإي مستويات التعلم الثلاثة: " المعرفة، والتطبيق، والاستكلال" لصالح

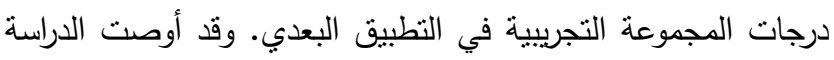

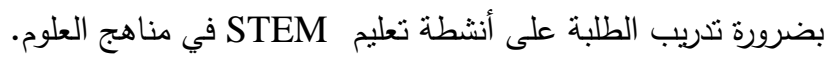

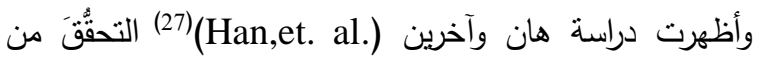
تفاعل أنشطة تعليمSTEMالقائمة على التعلم المبني على المشروع PBL باختلاف المستويات: "عالٍ، ومتوسط، وضعيف التحصيل"،

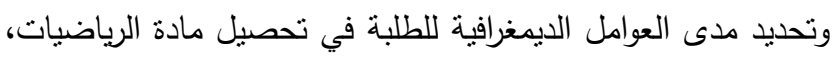

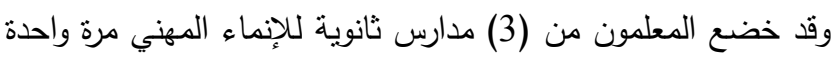

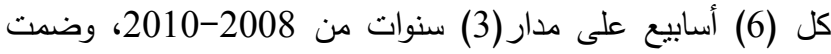

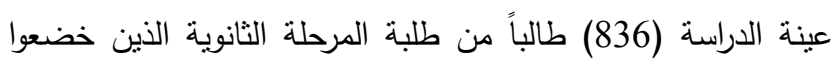
لاختبار خاص في المعارف والمهارات في ولاية تكساس الأمريكية، وقد أكدت نتائج الدراسة أن تعليم STEM القائم على التعلم المبني

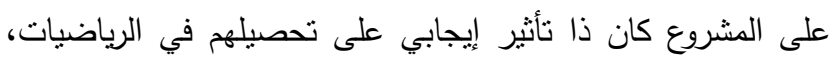
باختلاف مسنوياتهم.

وهدفت دراسة هرنادز وآخرين (Hernandez,et. al.)(29) إلى مئى

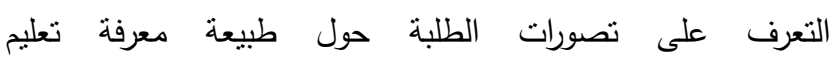
STEM ونطورها، وقد نفذت الدراسة في (5) مدارس ثانوية في ولاية

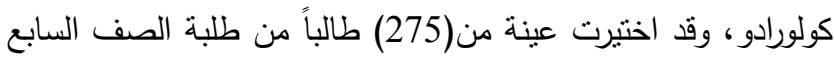
إلى الصف الثاني عثر، وتم تشكيل فريق من معلمي

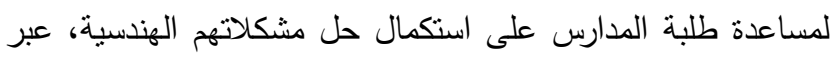

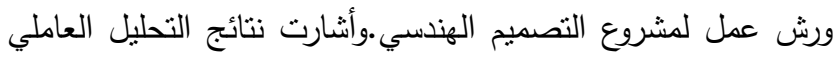
إلى أنّ التصورات كانت منخفضة في الاختبار القبلي مقارنة بالاختبار البَعدي، وأن التدخل من خلال ورش التصميم الهندسي كان ذا تأثير

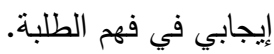
وفي دراسة أجراها (Drake \& Long)(19) في الولايات المتحدة الأمريكية على عينة من طلبة الصف الرابع الذين تلقًَّا

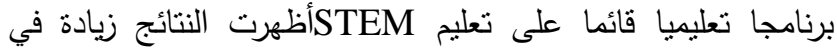

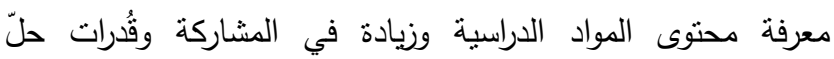

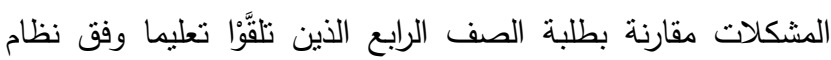
التندريس النقليدي.

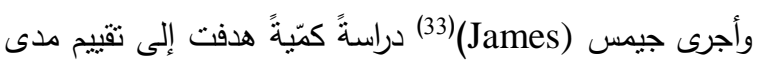
تأثثر تعليم STEM في تحصيل طلبة الصف السابع في مادة العلوم

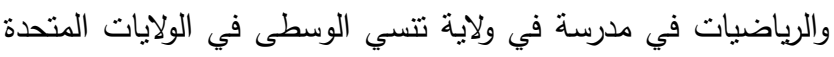

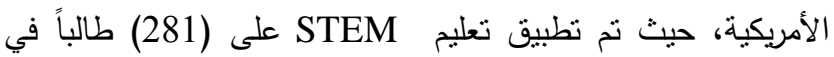


أداة الدراسة

Critical California اختبار كاليفورنيا لمهارات التفكير الناقد

.Thinking Skills Test

أعد هذا الاختبار فاثشيون عام (1992) للطلاب من الصف

العاشر وحتى المرحلة الجامعية. ويتكون من صورتين تحتوي كل منهما على (34) فقرة من نوع الاختيار من متعدد. لكل فقرة إجابة ونكان واحدة صحيحة، ويقيس هذا الاختبار مهارات التحليل، والتقويم، والاستتاج، والاستدلا الاستتباطي، والاستدلال الاستقرائي وتم

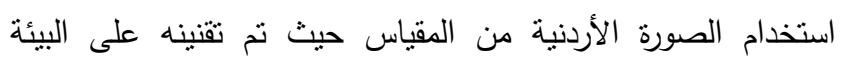
الأردنية عام 2003،(شطناوي) (9).

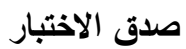

اعتمد الباحثون في ذلك على الصدق الظاهري، وقد تحقق هذا النوع من الصدق من خلال عرض اختبار كاليفورنيا لمهارات التفكير

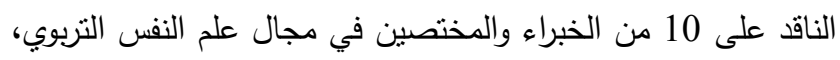
وعلم النفس المعرفي، والمناهج والتدريس، والقياس والتقويم لإقرار

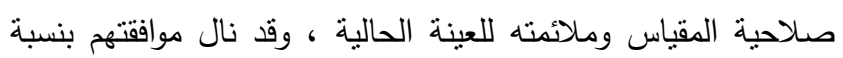

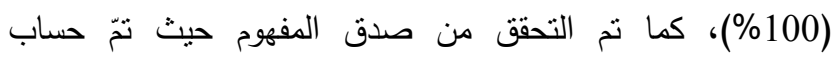
معاملات الارتباط بين الفقرة والدرجة الكلية وتراوحت معات معاملات الارتباط ما بين (0.45- 0.76) ، كما نم التحقق من معاملات

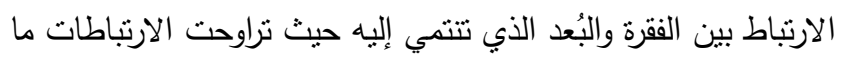
بين (0.48 - 0.76) وهي معاملات ارتباط جيدة ودالة إحصائياً، مدّا سبق تبيّن أن المقياس صالحّ للتطبيق.

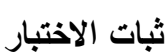

اعتمد الباحثون في حساب الثبات طريقة التجزئة النصفية وقد

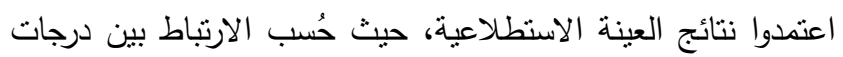
الوحدات الفردية ودرجات الوحدات الزوجية للمهارات كـ (مهارة التحليل Analysis Skill، مهارة الاستقراء Induction Skill،

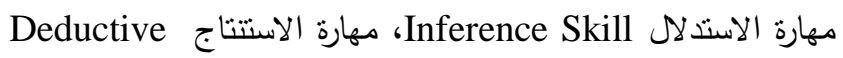

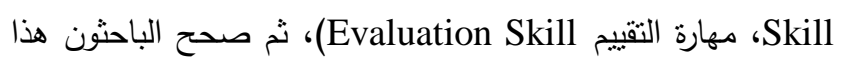
الارتباط باستعمال معادلة سبيرمان - براون حيث نراوحت معاملات

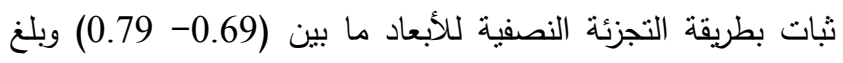
معامل الثبات بطريقة التجزئة النصفية للمقياس ككل (0.82). كما تم

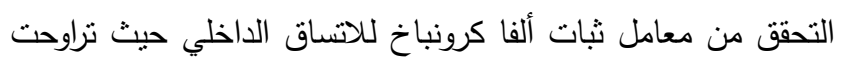

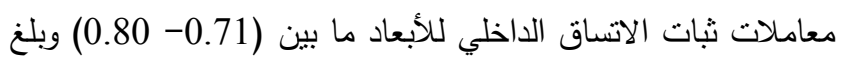

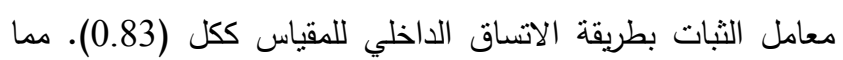
سبق تبين أنّ المقياس ينصف بالثبات وقابل للنطبيق.

أساليب المعالجة الإحصائية:

للإجابة عن أسئلة الدراسة استخدم الباحثون الأساليب

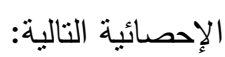

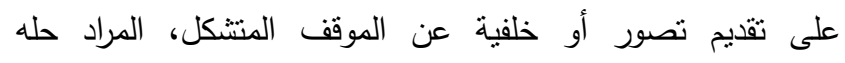
بالجلسة(المشكلة، التحدي)، وبعد ذللك عُدّ اجتماعٌ مع المعلمين المنعاونين والمعلمات المتعاونات لتوزيع الأدوار التدريسية بينهم وتحديد الإجراءات المتبعة، وكذلك توزيع الأدوار بين الطلبة لإنبات

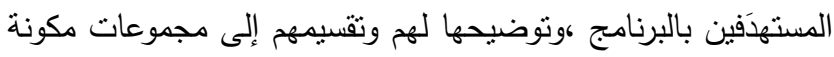

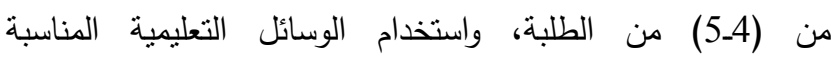
(المختبرات المختلفة، السبورة التفاعلية،الوسائط المتعددة...)، وتم التأكيد على تحقيق مبدأ التوازن بين التفكير التباعدي، والتفكير

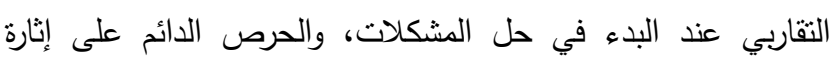

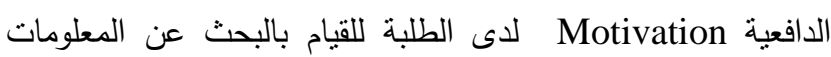
Relation Information وذلك لربطها Seeking Information مع الموقف الجديد وصولا إلى مرحلة التقويم Evaluation، وأخيرا التعبير، حيث يُعلن أفراد المجموعة المستهافة قابلية الحل للمراجعة والنقد.

\section{مجتمع الاراسة}

تكوّن مجتمعُ الدراسة من جميع طلبة الصف الأول ثانوي في

مدارس منطقة الرياض التعليمية.

عينة الدراسة

تكونت عينة الدراسةمن(88) طالباً وطالبة من طلبة الصف

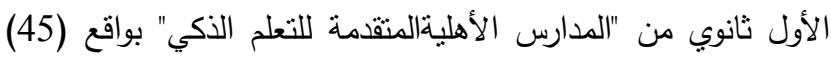

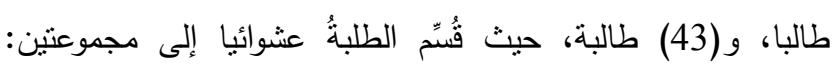
تجريبية وضابطة بواقع (45) طالبا للمجموعة التجريبية، و (43) طالباً للمجموعة الضابطة.

\section{إجراءات تطبيق البرنامج التدريسي}

ضم البرنامج التدريسي مجموعة من الدروس والأدوات والأنشطة التي تّم تدريسها باستخدام منحى STEM، وذلك من خلال الوحدةالأولى (الاقترانات كثيرات الحدود)، والوحدة الثانية (الاقترانات) من كتاب الرياضيات للصف الأول ثانوي المعتدد من قبل وزارة التربية

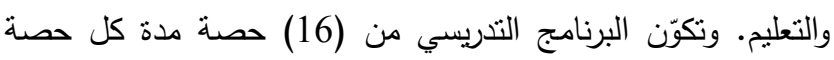

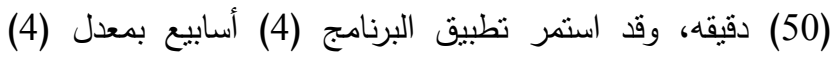
حصص في كل أسبوع. تم البدء بنطبيق البرنامج التدريسي في بداية الفصل الدراسي الأول للعام الدراسي 2018-2019م وذلك بإعطاء وحدة تعريفية اللبرنامج التدريسي، نم من خلالها تعريف الطلبة بمفردات البرنامج وأهدافه وأهميته، وكذلك كيفية سير الدروس والجانب التنظيمي. وتن

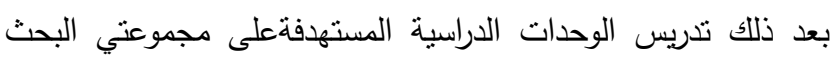

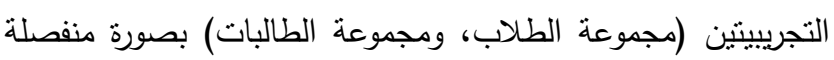

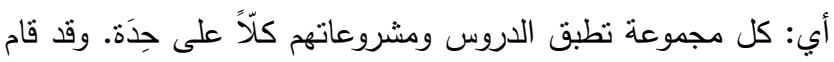
الباحثون بالإثراف المباثر على تطبيق البرنامج التدريسي بأكمله. 
جدول (1) يبين المتوسطات الحسابية والانحرافات المعيارية ونتائج اختبار (ت)

\begin{tabular}{|c|c|c|c|c|}
\hline للاتحراف & الحستوسطي & العينة & المجموعة & المهارة \\
\hline 0.53 & 1.75 & 44 & الضابطة & \multirow{2}{*}{ التحليل } \\
\hline 0.58 & 3.89 & 44 & التجريبية & \\
\hline 0.55 & 1.80 & 44 & الضابطة & \multirow{2}{*}{ الاستقراء } \\
\hline 0.60 & 3.91 & 44 & التجريبية & \\
\hline 0.88 & 4.02 & 44 & الضابطة & \multirow{2}{*}{ الاستدلال } \\
\hline 1.09 & 9.07 & 44 & التجريبية & \\
\hline 0.50 & 1.57 & 44 & الضابطة & \multirow{2}{*}{ الاستتتاج } \\
\hline 0.50 & 4.18 & 44 & التجريبية & \\
\hline 0.65 & 1.95 & 44 & الضابطة & \multirow{2}{*}{ التقييم } \\
\hline 0.91 & 4.09 & 44 & التجريبية & \\
\hline 1.94 & 10.11 & 44 & الضابطة & \multirow{2}{*}{ ككل المقياس } \\
\hline 2.58 & 21.89 & 44 & التجريبية & \\
\hline
\end{tabular}

ثانياً: عرض ومناقثة النتائج المتعلقة بالسؤال الثاني: لا يوجد

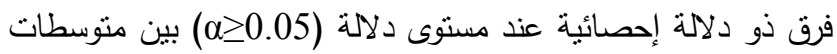
درجات طلبة المجموعة التجريبية، ودرجات المجموعة الضابطة

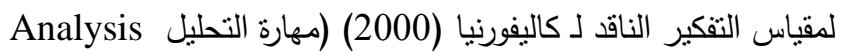
Skill، مهارة الاستقراء Induction Skill، مهارة الاستدلال Inference Skill التقييم Evaluation Skill) تُعزى لمتغير الجنس(ذكر ، أنثى). للإجابة عن السؤال الثاني تم حساب المنوسطات الحسابية والانحرافات

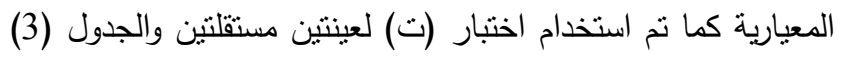
يبين ذلك. يتبين من خلال جدول (2) وجود فروق دالة إحصائياً بين متوسطات درجات مهارة التحليل حيث بلغت قيمة اختبار (ف=315.14) وهي قيمة دالة إحصائيا ولصالح المجموعة التجريبية.

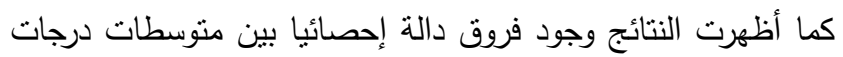
مهارة الاستقراء، حيث بلغت قيمة اختبار (ف=288.97) وهي قيمة دالة إحصائيا ولصالح المجموعة التجريبية. كما تبين وجود فروق دالة إحصائيا بين متوسطات درجات مهارة الاستدلالحيث قيمة اختبار (ف=585.57) وهي قيمة دالة إحصائيا ولصالح المجموعة التجريبية.

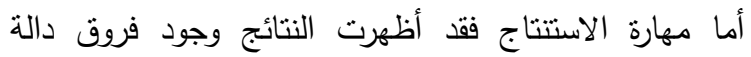
إحصائيا بين متوسطات الدرجات حيث بلغت فيمة اختبار

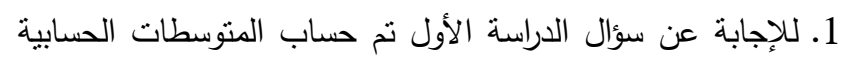
والانحرافات المعيارية، كما نم استخدام تحليل التباين الششترك. باعنبار الاختبار القبلي متغير التغاير. للإجابة عن سؤال الدراسة الثاني نم حساب المتوسطات التابئ الحسابية والانحرافات المعيارية كما نم استخدام اختبار (ت) لعينتين مستقلتين.

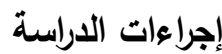

نُفّتت الدراسة وفقاً للإجراءات التالية:

1. تمّ الرجوع إلى الأدب النظري المتعلق بموضوع الدراسة.

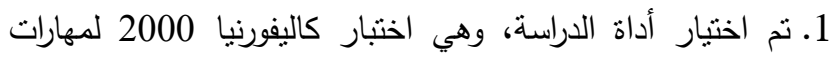

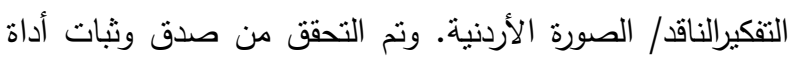

$$
\text { الدراسة. }
$$

1. نطبيق الأداة بصورتها النهائية على العينة المستهدفة من طلبة الصف الأول ثانوي في المدارس المتقدمة للتعلم الذكي في مدينة

$$
\text { عرض نتائج الدراسة في السعودية. }
$$

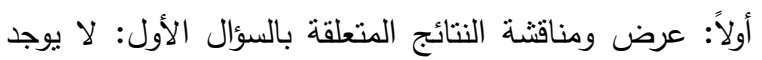

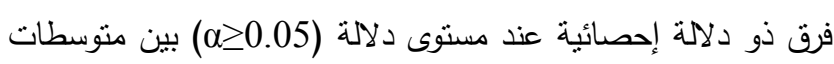
درجات طلبة الجموعة التجريبية، ودرجات المجموعة الضابطة لمهارات مقياس التفكير الناقد لـ كاليفورنيا (2000) (مهارة التحليل Analysis Skill الاستخ لا Skill مهارة التقييم Evaluation Skill) تُعزى لطريقة التشريس (استخدام برنامج تدريسي قائم على منحى STEM في تدريس الرياضيات،

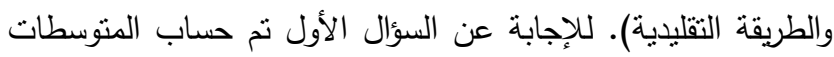
الحسابية والانحرافات المعيارية كما نم استخدام اختبار تحليل التباين المشترك والجدول (1) يبين ذلك.

يتبين من خلال جدول (1) وجود فروق ظاهرية بين منوسطات درجات الطلبة على مهارات مقياس التفكير الناقد حيث تراوحت

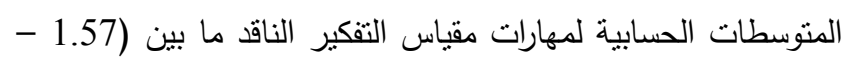

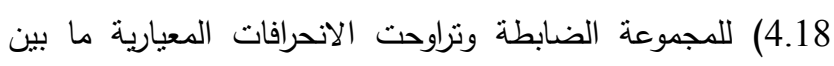
(4) 0.50) وتراوحت المتوسطات الحسابية للمجموعة التجريبية ما بين ( 3.89 - 9.07) والانحرافات المعيارية ما بين (0.50 - 0.07 1.09) كما بلغ المنوسط الحسابي للارجة الكلية للمجموعة الضابطة (10.11) بانحراف معياري (1.94) والمجموعة التجريبية (21.89) بانحراف معياري (2.58). وللتحقق من جوهرية الفروق بين المنوسطات نم استخدام اختبار تحليل التباين المشترك لمناسبته وذلك الك باعتبار الاختبار القبلي متغير التغاير. وجدول (2) بيين نتائج ذلك. 
(ف=593.44) وهي قيمة دالة إحصائيا ولصالح الهجموعة فروق دالة إحصائيا بين منوسطات درجات مهارات المقياس ككل

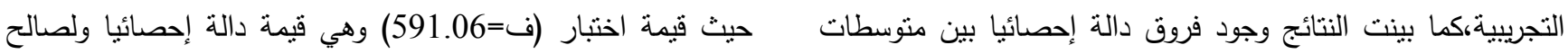

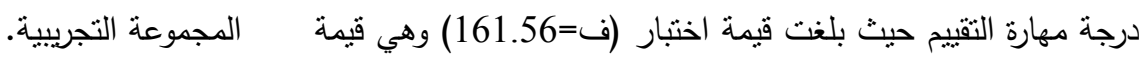

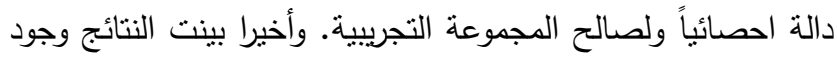

جدول (2) نتائج اختبار تحليل التباين المشترك.

\begin{tabular}{|c|c|c|c|c|c|c|}
\hline الدلالة الاحصائية & اختبار (ف) & متوسط المربعات & درجة الحرية & مجموع المربعات & مصدر النباين & المهارة \\
\hline 0.68 & 0.18 & 0.06 & 1.00 & 0.06 & الاختبار القبلي & \multirow{4}{*}{ التحليل } \\
\hline \multirow[t]{3}{*}{$0.00 *$} & 315.14 & 98.72 & 1.00 & 98.72 & المجموعة & \\
\hline & & 0.31 & 85.00 & 26.63 & الخطأ & \\
\hline & & & 87.00 & 127.09 & الكلي & \\
\hline 0.62 & 0.24 & 0.08 & 1.00 & 0.08 & الاختبار القبلي & \multirow{4}{*}{ الاستقراء } \\
\hline \multirow[t]{3}{*}{$0.00^{*}$} & 288.97 & 97.62 & 1.00 & 97.62 & المجموعة & \\
\hline & & 0.34 & 85.00 & 28.71 & الخطأ & \\
\hline & & & 87.00 & 127.08 & الكلي & \\
\hline 0.09 & 2.92 & 2.78 & 1.00 & 2.78 & الاختبار القبلي & \multirow{4}{*}{ الاستدلال } \\
\hline \multirow[t]{3}{*}{$0.00 *$} & 585.57 & 557.95 & 1.00 & 557.95 & المجموعة & \\
\hline & & 0.95 & 85.00 & 80.99 & الخطأ & \\
\hline & & & 87.00 & 643.82 & الكلي & \\
\hline 0.51 & 0.45 & 0.11 & 1.00 & 0.11 & الاختبار القبلي & \multirow{4}{*}{ الاستتناج } \\
\hline \multirow[t]{3}{*}{$0.00^{*}$} & 593.44 & 148.21 & 1.00 & 148.21 & المجموعة & \\
\hline & & 0.25 & 85.00 & 21.23 & الخطأ & \\
\hline & & & 87.00 & 171.63 & الكلي & \\
\hline 0.36 & 0.86 & 0.53 & 1.00 & 0.53 & الاختبار القبلي & \multirow{4}{*}{ التقييم } \\
\hline \multirow[t]{3}{*}{$0.00 *$} & 161.56 & 100.76 & 1.00 & 100.76 & المجموعة & \\
\hline & & 0.62 & 85.00 & 53.01 & الخطأ & \\
\hline & & & 87.00 & 153.96 & الكلي & \\
\hline 0.11 & 2.56 & 13.14 & 1.00 & 13.14 & الاختبار القبلي & \multirow{4}{*}{ المقياس ككل } \\
\hline \multirow[t]{3}{*}{$0.00 *$} & 591.06 & 3029.91 & 1.00 & 3029.91 & المجموعة & \\
\hline & & 5.13 & 85.00 & 435.73 & الخطأ & \\
\hline & & & 87.00 & 3498.00 & الكلي & \\
\hline
\end{tabular}

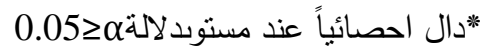

جدول (3) نتائج المتوسطات الحسابية والانحرافات المعيارية ونتائج اختبار ت لعينتين مستقلتين تبعاً لمتغير الجنس (ذكر ، أنثى)

\begin{tabular}{|c|c|c|c|c|c|c|c|}
\hline الاحصائية & درجة الحرية & $\begin{array}{l}\text { اختبار } \\
\text { (ت) }\end{array}$ & الانحراف & الحسابي & العينة & المجموعة & المهارة \\
\hline \multirow{2}{*}{0.67} & \multirow{2}{*}{86} & \multirow{2}{*}{0.43} & 1.17 & 2.77 & 47 & ذكر & \multirow{2}{*}{ التحليل } \\
\hline & & & 1.27 & 2.88 & 41 & انثى & \\
\hline \multirow{2}{*}{0.48} & \multirow{2}{*}{86} & \multirow{2}{*}{0.72} & 1.15 & 2.77 & 47 & ذ ذكر & \multirow{2}{*}{ الاستقراء } \\
\hline & & & 1.28 & 2.95 & 41 & أنثى & \\
\hline
\end{tabular}


المجلة الدولية لضمان الجودة - المجلد الثالث - العدد الثاني، 2020.

\begin{tabular}{|c|c|c|c|c|c|c|c|}
\hline \multirow{2}{*}{0.79} & \multirow{2}{*}{86} & \multirow{2}{*}{0.26} & 2.74 & 6.62 & 47 & ذكر & \multirow{2}{*}{ الاستدلال } \\
\hline & & & 2.73 & 6.46 & 41 & أنثى & \\
\hline \multirow{2}{*}{0.99} & \multirow{2}{*}{86} & \multirow{2}{*}{0.02} & 1.38 & 2.87 & 47 & ذكر & \multirow{2}{*}{ الاستتناج } \\
\hline & & & 1.45 & 2.88 & 41 & أنثى & \\
\hline \multirow{2}{*}{0.74} & \multirow{2}{*}{86} & \multirow{2}{*}{0.33} & 1.15 & 2.98 & 47 & ذكر & \multirow{2}{*}{ التقييم } \\
\hline & & & 1.52 & 3.07 & 41 & أنثى & \\
\hline \multirow{2}{*}{0.92} & \multirow{2}{*}{86} & \multirow{2}{*}{0.10} & 6.58 & 16.06 & 47 & ذكر & \multirow{2}{*}{ لدرجة الكلية } \\
\hline & & & 6.13 & 15.93 & 41 & أنثى & \\
\hline
\end{tabular}

لـ (مهارة التحليل Anduction Analysis Skill، مهارة الاسنقراء Skill مهارة الاستدلال Inference Skill، مهارة الاستنتاج

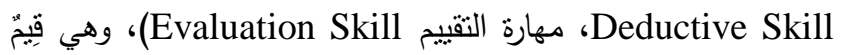
دالة إحصائيا ولصالح طلبة المجموعة التجريبية.أي أنّ أداء الطلبة، وهئ الذين تمّ تدريسهم وفق البرنامج التدريسي القائر على منحى STEM على مقياس التفكير الناقد لـ كاليفورنيا (2000) أفضل من أداء الطلبة الذين تم تدريسهم وفق الطريقة التقليدية الكُقرَّة مِن قبل وزارة التربية والتعليم في المملكة العربية

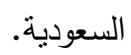
ويمكن تفسير هذه النتيجة في أنّ توجهات التعليم في القرن الحادي والعشرين تدعو إلى دمج موضوعات العلوم والتقنية والهندسة والرياضيات من أجل تتمية مهارات التفكير العلمي، وتحقيق نصميم

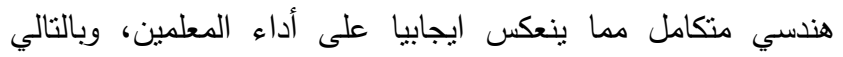

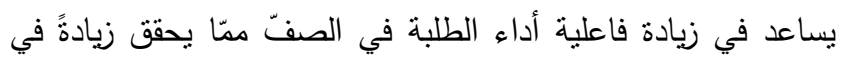
جودة مُخرجات النظام التعليمي.وقد تُعزى هذه النتيجة من وجهة نظر

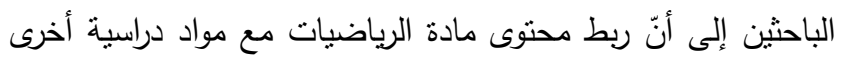
كالعلوم بفروعه عامة والهندسة، والتكنولوجيا، نساعد على تنمية

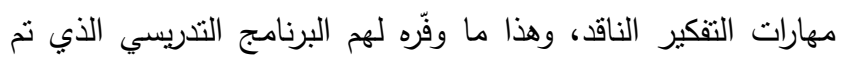

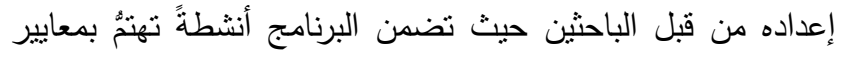

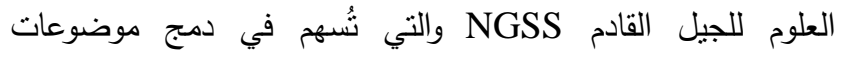

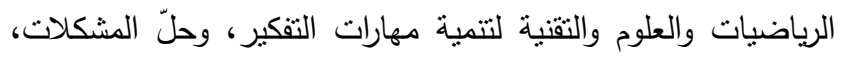

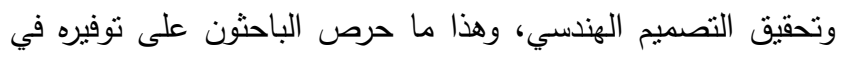
البرنامج التدريسي. كما يمكن عَزُْو هذه النتيجة إلى أنّ استخدام منحى STEM

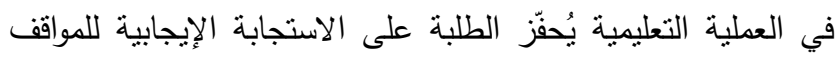

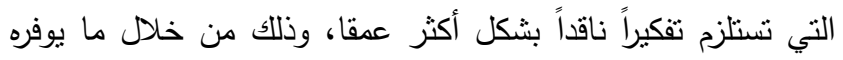

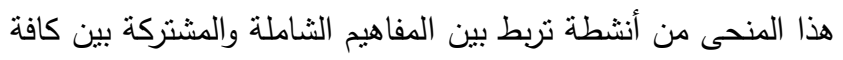

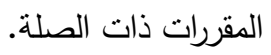

ويري الباحثون أنّ تعليم مادة الرياضيات من خلال الاعتماد على منحى STEM يساعد في تحويل الدفاهيم الرياضية المجردة، إلى نطبيقات ملموسة بشكل عملي؛ مما بساعد على نرسيخ الدفاهيم

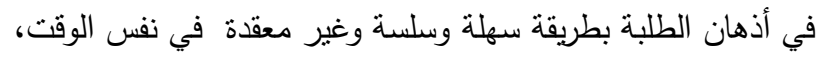

يتبين من خلال جدول (3) عدم وجود فروق دالة إحصائياً بين متوسطات درجات مهارة التحليل حيث بلغ المنوسط الحسابي للاكور

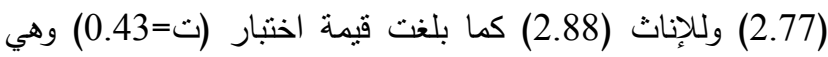

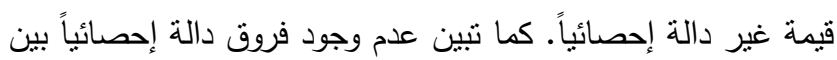
متوسطات درجات مهارة الاستقراء حيث بلغ المتوسط الحسابي للاكور

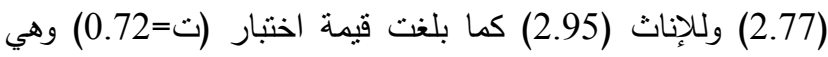

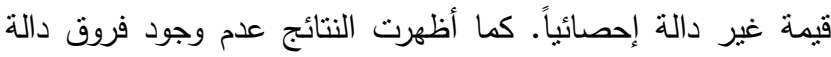
إحصائيا بين متوسطات درجات مهارة الاستدلال حيث بلغ المتوسط

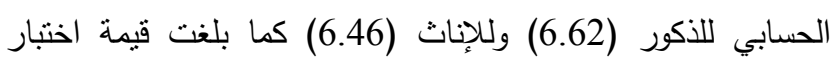

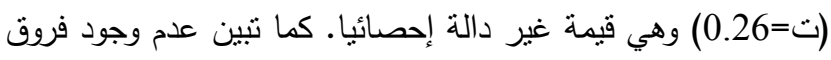

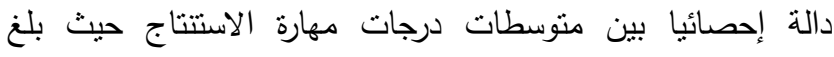
المتوسط الحسابي للذكور (2.87) وللإناث (2.88) كما بلغت قيمة لئن اختبار (ت=0.02) وهي قيمة غير دالة إحصائيا. أما مهارة التقييم فقد

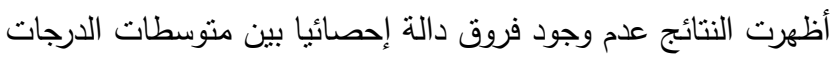

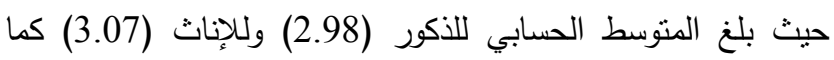
بلغت قيمة اختبار (ت=0.33) وهي قيمة غير دالة إحصائيا. وأخيراً

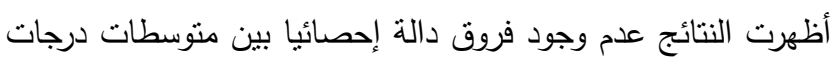

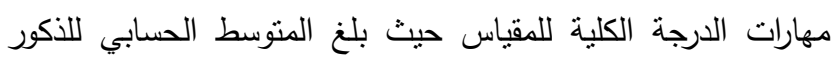

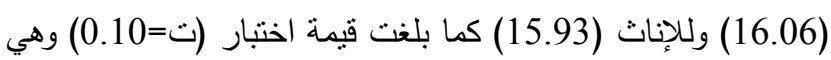

قيمة غير دالة إحصائيا.

مناقثة النتائج

\section{اولا: مناقشة النتائج المتعلقة بالفرضية الأولى}

لا يوجد فرق ذو دلالة إحصائية عند مستوى دلالة (1<0.05)

بين متوسطات درجات طلبة المجموعة التجريبية، ودرجات المجموعة الضابطة لمقياس التفكير الناقد لـ كاليفورنيا (2000) لـ (مهارة التحليل Analysis Skill

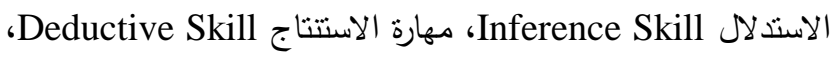
مهارة التقييم Evaluation Skill) تُعزى لاستخدام برنامج تدريسي في الرياضيات قائمٍ على منحى STEM مهئمة أظهرت نتائج الدراسة وجود فروق دالة إحصائية عند مستوى

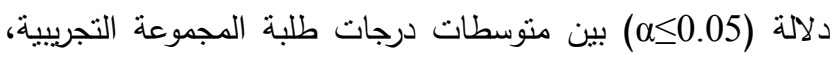
ودرجات المجموعة الضابطة لمقياس النقكير الناقد كاليفورنيا (2000) لئن 
السعودية. مع نتائج دراسة هان وآخرون (Han,et. al.)(27) التي هدفت إلى التحقق من تفاعل أنشطة تعليم STEM القائمة على التعلم المبني على المشروع PBL باختلاف المستويات" عالي، ومنوسط،

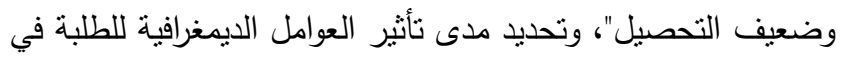

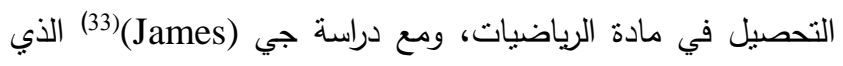

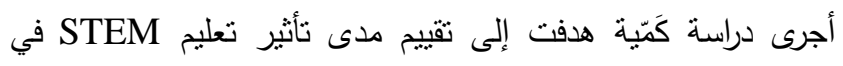

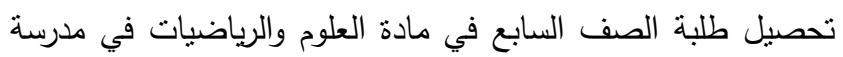
في ولاية تتسي الوسطى في الولايات المتحدة الأمريكية.

\section{ثانيا: مناقثة النتائج المتعلقة بالفرضية الثانية}

لا يوجد فرق ذو دلالة إحصائية عند مستوى دلالة (a $(\alpha .05)$

بين منوسطات درجات طلبة المجموعة التجريبية، ودرجات المجموعة الضابطة لدقياس التفكير الناقد لـ كاليفورنيا (2000) (مهارة التحليل Analysis Skill الاستخلال Inference Skill، مهارة الاستتناج Deductive Skill، مهارة التقييم Evaluation Skill) تُعزى لمتغير الجنس ( ذكر ،

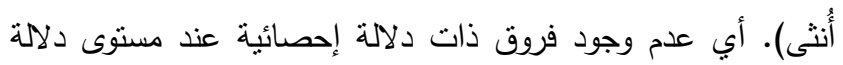

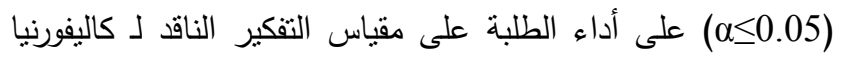

$$
\text { (2000) تُعزى لمتغير الجنس (ذكر ، أنثى). }
$$

وقد تُعزى هذه النتيجة من وجهة نظر الباحثين إلى تبنّي وزارة

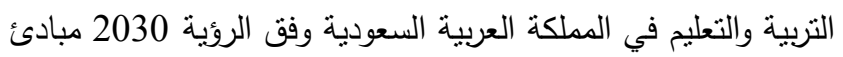

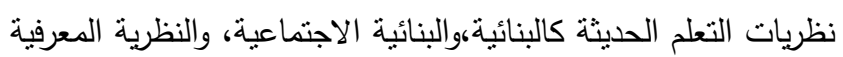
في عملية التعلم والتعليم، والحرص الثديد من قبل الوزارة نحو اعتماد استراتيجيات حديثة في التخطيط والتدريس والتقويم، والاستثمار الأمثل

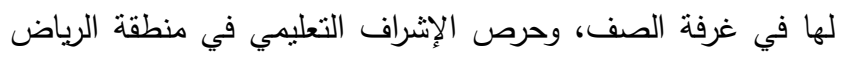

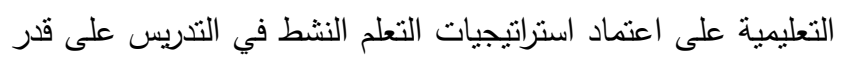

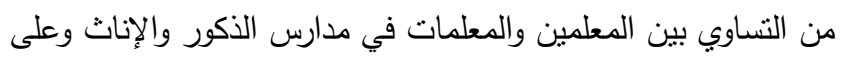

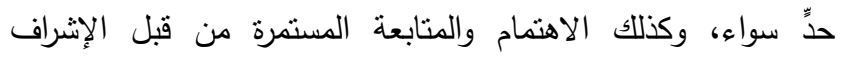
التعليمي الخاص بالمعلمين والمعلمات على تطبيق هذه الاستراتيجيات الحديثة أثثاء عملية التدريس. وكذلك حرص الددارس على على منابعة

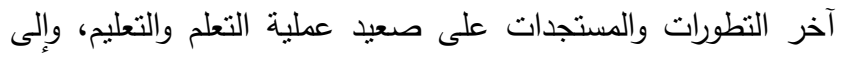
تثابه ظروف العمل ودرجة الاهتمام بتعلم الطلبة عند كل من

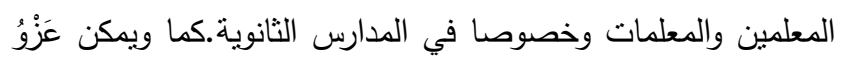

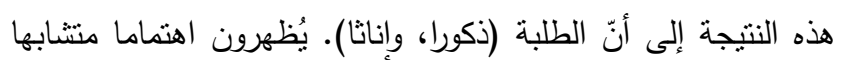

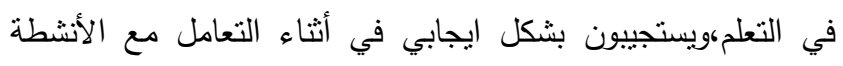
والتدريبات ومواقف التعلم المختلفة، حيث لاحظ الباحثون ذلك أثناء تطبيق البرنامج التدريسي.
والذي بدوره يؤدي إلى نطوير وتتمية مهارات التفكير العليا

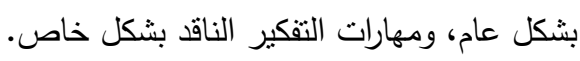
ويمكن تقسير هذه النتيجة في جانب منها إلى ما تمتاز به وحدة

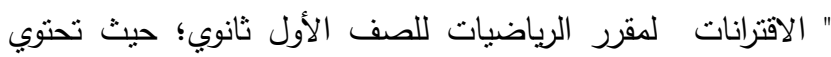
على مفاهيم شاملة ذات ارتباط وثيق نوعا ما بمجالات وموضوعات الفيزياء والهندسة والتكنولوجيا، وعملية دمج هذه الموضوعات من

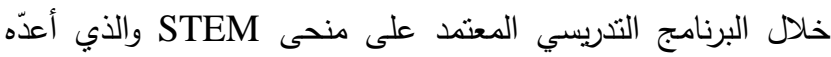

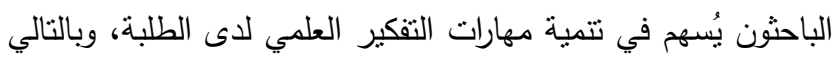

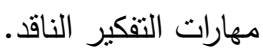
هذا ويعتد البرنامج الندريسي المستتد إلى منحى التصى توظيف التقنيات والوسائل التعليمية الحديثة في ممارسة العملية التعليمية؛ وذللك لها له من أثر كبير نحو التعلم والإبداع، وتتمبية

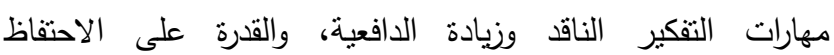
بالمعلومات لفترات زمنية طويلة، وتحقيق الرضا عن بيئة النعليم باعنبارها بيئة تناعلية. وقد اتفقت نتائج هذه الدراسة المنمتلة في أنّ أداء الطلبة الذين

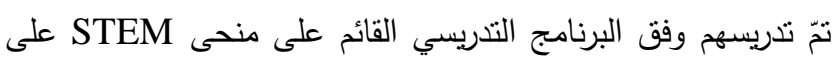
مقياس التفكير الناقد لـ كاليفورنيا (2000) أفضل من ألفرئي أداء الطلبة الذين نم تدريسهم وفق الطريقة الاعتيادية الكُقرّة من قبل وزارة التربية

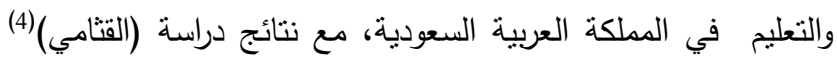
في وجود أثر ايجابي على التحصيل في مادة الرياضيات لدى الطلبة

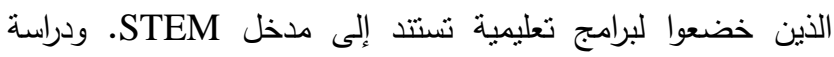

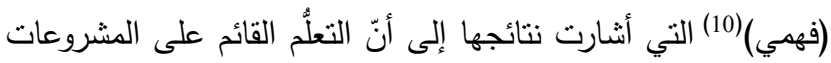

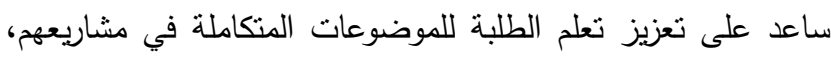

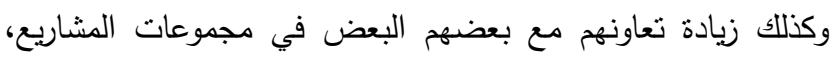
وإلى أنّ مستوى درجات الطلبة بجانب تعرضهم السابق للتعلم القائم على المشروعات قد أثّر في تصوراتهم على ذلك التعلم. وكذلك اتفقت

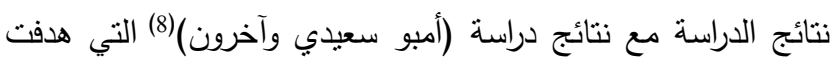

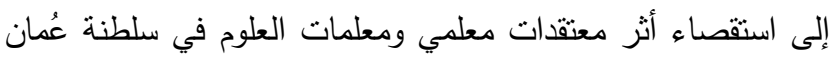
نحو تدريس موضوعات كل من العلوم والتقنية والهندسة والرياضيات

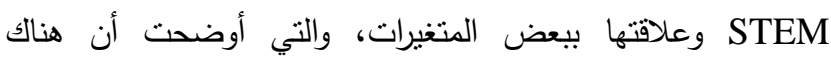
معتقدات عالية لاى المعلمين والمعلمات نحو تدريس موضوعات

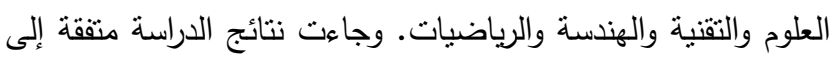

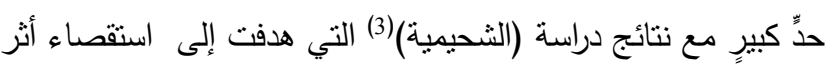
استخدام تعليم STEM في التفكير الإبداعي، والتحصيل في مادة

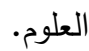
وبالنسبة للدراسات الأجنبية فقد اتفقت نتائج هذه الدراسة

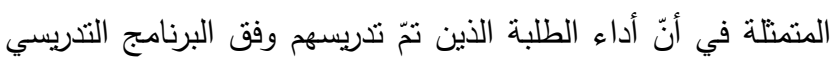
القائم على منحى STEM على مقياس التفكير الناقد لـ كاليفورنيا (2000) أفضل من أداء الطلبة الذين نم تدريسهم وفق الطريقة الاعتيادية المُقرّة من قبل وزارة التربية والتعليم في المملكة العربية 
Sultanate of Oman in the Direction of Science, Technology, Engineering and Mathematics, STEM. The Excellence in Science and Mathematics Education First Conference on Science, Technology, Engineering and Mathematics Directives STEM, (pp. 391-405). Riyadh.

9. Shatnawi, M., (2003). Legalization of the California Test of Critical Thinking Skills for Undergraduate Students in Jordan, Unpublished Master Thesis, University of Mutah Jordan.

10. Fahmi, H. A. (2016). A Survey on ProjectBased Learning at the School of Excellence for Science and Technology in Egypt. Cairo: The American University.

11. MacFarlane, B. (2015). STEM Curriculum Design for Gifted Students, STEM programming design and implementation. Riyadh: Obeikan Publishing

12. Agenda, A., Academy, N., \& Academy, N. (2007). Rising above the gathering storm: Energizing and employing America for a brighter economic future. In Rising Above the Gathering Storm: Energizing and Employing America for a Brighter Economic Future. https://doi.org/10.17226/11463

13. Astleitner, H. (2002). Teaching critical thinking. Perianesthesia and Ambulatory Surgery Nursing Update, Vol. 9, p. 59. https://doi.org/10.1057/9781137378057.0010

14. Bailin, S., Case, R., Coombs, J. R., \& Daniels, L. B. (1999). Conceptualizing critical thinking. Journal of Curriculum Studies, 31(3), 285-302. https://doi.org/10.1080/002202799183133

15. Barcelona, K. (2014). $21<$ SUP $>$ st $</$ SUP $>$ Century Curriculum Change Initiative: A Focus on STEM Education as an Integrated Approach to Teaching and Learning. American Journal of Educational Research, 2(10), 862-875. https://doi.org/10.12691/education-2-10-4

16. Bransford, J. (2000). How People Learn: Brain, Mind, Experience, and School: Expanded Edition DETAILS. In How people learn: Brain, Mind, Experience, and School. https://doi.org/10.17226/9853

17. Brookfield, S. D. (1993). Understanding consulting as an adult education process. New Directions for Adult and Continuing Education, 1993(58), https://doi.org/10.1002/ace.36719935803

18. Carin, A.A. \& Sund, R.B, Tsupros, N. (2009). STEM education: A project to identify the missing components. Pennsylvania: Intermediate Unit 1: Center for STEM Education and Leonard Gelfand Center for Service Learning and Outreach. Retrieved from
التوصيات

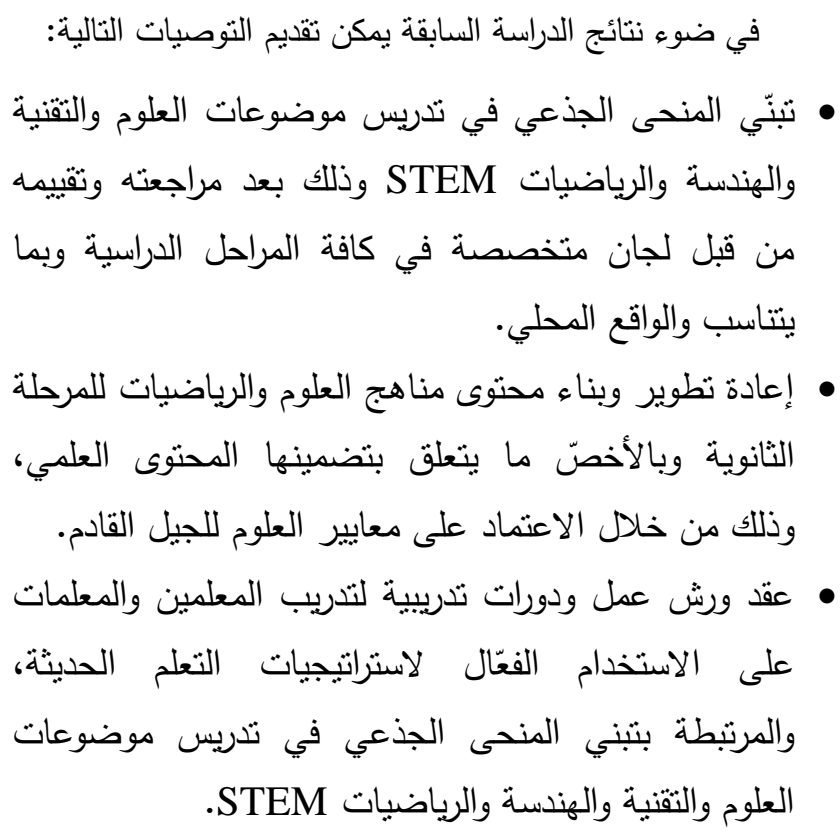

\section{References}

1. Abu Hatab (2013). Educational psychology. The Anglo Egyptian Library.

2. Al Bashir (2012). Towards Optimal Methods of Teaching Science. Retrieved 12 10, 2019, from Diyarna Comprehensive Network: http://www.ourfull.net/articles-action-show-id2807.htm

3. Al Shuhaimia (2015). The Effect of Using the STEM Approach in Developing Creative Thinking and Science Achievement for Third Grade Students. Sultanate of Oman: Sultan Qaboos University .

4. Al Qothami, P. A. (2017). The Effect of Using the STEM Approach to Teaching Mathematics on Academic Achievement and Thinking Skills for Second Medium Grade. Mecca: Umm AlQura University.

5. Al Maleki, M. M. (2018). The Effectiveness of Science Education at the STEM Entrance in Developing Research Skills with ISEF Standards for Primary School Students. Jeddah: Jeddah Education Administration.

6. Jarwan, F. P. (2016). Talent and Excellence. Amman: Dar Al-Fikr for publication and distribution

7. Khaja, P., \& Muheisen, A. (2015). Professional Development for Science Teachers in Light of STEM Integration. Research presented to the first conference in excellence in learning and teaching science and mathematics. Riyadh: King Saud University.

8. Saeidy, A., Al-Shehmeia, A. P., Bint Amer, A. (2015). The Beliefs of Science Teachers in the 

Education,
24
(1),
107-120.

https://doi.org/10.1007/s10798-013-9241-0

30. Honey, M. A., Pearson, G., \& Schweingruber, H. (2014). STEM integration in K-12 education: status, prospects, and an agenda for research. In STEM Integration in K-12 Education: Status, Prospects, and an Agenda for Research. https://doi.org/10.17226/18612

31. Huitt, W. (1998). Critical thinking: An overview. Educational Psychology Interactive. Retrieved December 6, 2019, from http://www.edpsycinteractive.org/topics/cognitio n/critthnk.html

32. Jacques, C., \& Brorsen, B. W. (2002). Relationship between types of school district expenditures and student performance. Applied Economics Letters, 9(15), 997-1002. https://doi.org/10.1080/13504850210148161

33. James, J. S. (2014). Science, Technology, Engineering, and Mathematics STEM Curriculum and Seventh Grade Mathematics and Science Achievement. ProQuest LLC.

34. Koppes, S. (2015). Study identifies common elements of STEM schools. Retrieved December 20, 2019 from http://news.uchicago.edu/article/2015/01/27/stud y-identifies-common-elements-stemschools,

35. MacFarlane, B. (2016). Dumbing Down America: The War on Our Nation's Brightest Young Minds (And What We Can Do to Fight Back). Delisle, J. (2014) . Roeper Review, 38(1), 57-58.

https://doi.org/10.1080/02783193.2016.1112720

36. Mann, A., \& Oldknow, A. (2012). Schoolindustry STEM links in the UK: A report commissioned by Futurelab. Retrieved from http://www.futurelab.org.uk/resources/schoolindustry-stem-links-uk

37. Ministry of Education. (2010). Departments of Education in the kingdom of Saudi Arabia. Retrieved December 20, 2019, from https://www.moe.gov.sa/Pages/ministryguide.as px

38. Robinson, K. (2015). Creative Schools: The Grassroots Revolution That's Transforming Education. Ken Robinson and Lou Aronica. New York: Viking Press, 2015. 292 pages. Journal of Educational Research and Innovation, $5(1), 4$.

39. Sander, M. (2009). STEM, STEM Education, STEMmania. Skin Research, 41(1), 49-52. https://doi.org/10.11340/skinresearch1959.41.49

40. Williams, P. J. (2011). STEM Education: Proceed with caution. In Design and Technology Education (Vol. 16).

41. Abu Hatab (2013). Educational psychology. The Anglo Egyptian Library. https://www.cmu.edu/gelfand/documents/stemsurvey-report-cmu-iu1.pdf

19. Drake, K. N., \& Long, D. (2009). Rebecca's in the dark: A comparative study of problem-based learning and direct instruction/experiential learning in two 4th-grade classrooms. Journal of Elementary Science Education, 21(1), 1-16. https://doi.org/10.1007/bf03174712

20. Dugger, W. E. (2014). Evolution of STEM in the United States. 6Th Biennial International Conference on Technology Education Research, (March), 1-8. https://doi.org/10.1.1.476.5804

21. Erdogan, N., \& Stuessy, C. L. (2015). Modeling Successful STEM High Schools in the United States: An Ecology Framework. International Journal of Education in Mathematics, Science and Technology, 3 (1), 77. https://doi.org/10.18404/ijemst.85245

22. Fang, Z. (2013). Disciplinary literacy in science developing science literacy through trade books. Journal of Adolescent and Adult Literacy, 57(4), 274-278. https://doi.org/10.1002/JAAL.250

23. Fisher, W. S. (2001). Critical thinking. In Microsurgery (Vol. $15)$. https://doi.org/10.1002/micr.1920150802

24. Gonzalez, H. B., \& J.Kuenzi, J. (2012). Science, technology, engineering, and mathematics STEM: A Primer. Congressional Research Service, (August), 1-15. Retrieved from https://www.ccc.edu/departments/Documents/S TEM_labor.pdf

25. Gordon, R., Kornberger, M., \& Clegg, S. R. (2009). Power, rationality and legitimacy in public organizations. Public Administration, 87(1), 15-34. https://doi.org/10.1111/j.14679299.2008.01743.x

26. Halpern, D. F. (1998). Teaching critical thinking for transfer across domains. American Psychologist, 53(4), 449-455. https://doi.org/10.1037//0003-066x.53.4.449

27. Han, S., Capraro, R., \& Capraro, M. M. (2015). How Science, Technology, Engineering, and Mathematics STEM Project-Based Learning (Pbl) Affects High, Middle, and Low Achievers Differently: the Impact of Student Factors on Achievement. International Journal of Science and Mathematics Education, 13(5), 1089-1113. https://doi.org/10.1007/s10763-014-9526-0

28. Harrison, M., \& Royal, T. (2011). Supporting the $\mathrm{T}$ and the E in STEM: 2004-2010. Design and Technology Education, 16(1), 17-25.

29. Hernandez, P. R., Bodin, R., Elliott, J. W., Ibrahim, B., Rambo-Hernandez, K. E., Chen, T. W., \& De Miranda, M. A. (2014). Connecting the STEM dots: Measuring the effect of an integrated engineering design intervention. International Journal of Technology and Design 
42. Al Bashir (2012). Towards Optimal Methods of Teaching Science. Retrieved 12 10, 2019, from Diyarna Comprehensive Network: http://www.ourfull.net/articles-action-show-id2807.htm

43. Al Shuhaimia (2015). The Effect of Using the STEM Approach in Developing Creative Thinking and Science Achievement for Third Grade Students. Sultanate of Oman: Sultan Qaboos University.

44. Al Qothami, P. A. (2017). The Effect of Using the STEM Approach to Teaching Mathematics on Academic Achievement and Thinking Skills for Second Medium Grade. Mecca: Umm AlQura University.

45. Al Maleki, M. M. (2018). The Effectiveness of Science Education at the STEM Entrance in Developing Research Skills with ISEF Standards for Primary School Students. Jeddah: Jeddah Education Administration.

46. Jarwan, F. P. (2016). Talent and Excellence. Amman: Dar Al-Fikr for publication and distribution.

47. Khaja, P., \& Muheisen, A. (2015). Professional Development for Science Teachers in Light of STEM Integration. Research presented to the first conference in excellence in learning and teaching science and mathematics. Riyadh: King Saud University.

48. Saeidy, A., Al-Shehmeia, A. P., Bint Amer, A. (2015). The Beliefs of Science Teachers in the Sultanate of Oman in the Direction of Science, Technology, Engineering and Mathematics, STEM. The Excellence in Science and Mathematics Education First Conference on Science, Technology, Engineering and Mathematics Directives STEM, (pp. 391-405). Riyadh.

49. Shatnawi, M., (2003). Legalization of the California Test of Critical Thinking Skills for Undergraduate Students in Jordan, Unpublished Master Thesis, University of Mutah Jordan.

50. Fahmi, H. A. (2016). A Survey on Project-Based Learning at the School of Excellence for Science and Technology in Egypt. Cairo: The American University.

51. MacFarlane, B. (2015). STEM Curriculum Design for Gifted Students, STEM programming design and implementation. Riyadh: Obeikan Publishing 